\title{
Influence of surface water variations on VOD and biomass estimates from passive microwave sensors
}

\author{
Emma Bousquet ${ }^{\mathrm{a}, *}$, Arnaud Mialon ${ }^{\mathrm{a}}$, Nemesio Rodriguez-Fernandez ${ }^{\mathrm{a}}$, Catherine Prigent ${ }^{\mathrm{b}}$, \\ Fabien H. Wagner ${ }^{c}$, Yann H. Kerr ${ }^{a}$ \\ ${ }^{\text {a } C e n t r e ~ d ' E t u d e s ~ S p a t i a l e s ~ d e ~ l a ~ B i o s p h e ̀ r e ~(C E S B I O), ~ U n i v e r s i t e ́ ~ d e ~ T o u l o u s e ~(C N E S / C N R S / I N R A E / I R D / U P S), ~} 18$ av. Edouard Belin, bpi 2801, 31401 Toulouse \\ CEDEX 9, France \\ ${ }^{\mathrm{b}}$ CNRS, Sorbonne Université, Observatoire de Paris, Université PSL, LERMA, 61 avenue de l'Observatoire, 75014 Paris, France \\ ${ }^{\mathrm{c}}$ GeoProcessing Division, Foundation for Science, Technology and Space Applications-FUNCATE, São José dos Campos, SP 12210-131, Brazil
}

\section{A R T I C L E I N F O}

\section{Editor: Jing M. Chen}

\section{Keywords:}

Biomass

Water fraction

Passive microwaves

SMOS

L-band

VOD

Retrievals

\begin{abstract}
A B S T R A C T
Vegetation optical depth (VOD) is a remotely sensed indicator characterizing the attenuation of the Earth's thermal emission at microwave wavelengths by the vegetation layer. At L-band, VOD is used to estimate the global biomass, a key component of the Earth's surface and of the carbon cycle. This study focuses on the behaviour of L-band VOD (L-VOD) retrieval algorithm over seasonally inundated areas, as some previous observations have shown an unexpected decline in VOD during flooding events. To analyse such variations, a passive microwave model was used to simulate the signal emitted by a mixed scene composed of soil and standing water. The retrieval over this inundated scene led to an overestimation of soil moisture (SM) and an underestimation of L-VOD. The phenomenon is more pronounced over grasslands than over forests, since low vegetation is mostly submerged under water and becomes invisible to the sensor; and since more standing water is visible to the sensor. The estimated L-VOD is typically reduced by $\sim 10 \%$ over flooded forests and up to $100 \%$ over flooded grasslands. Such effects can distort the analysis of aboveground biomass (AGB) and aboveground carbon (AGC) dynamics based on L-VOD estimates. We evaluated that AGB can be underestimated by $15 / 20 \mathrm{Mg}$ $\mathrm{ha}^{-1}$ in the largest seasonal wetlands, which can represent more than $50 \%$ of the actual AGB of these fields, and up to higher values during exceptional meteorological years. Consequently, to better estimate the global biomass, surface water seasonality has to be taken into account in passive microwave retrieval algorithms.
\end{abstract}

\section{Introduction}

Large-scale monitoring of vegetation cover is crucial for understanding its behaviour and its links with climate evolution, extreme events, and land cover changes (Piao et al., 2019; Qin et al., 2019). Visible frequencies have predominantly been used for these applications, thanks to the high spatial resolution of optical instruments. They are however impaired by their inability to penetrate clouds and dense vegetation. Passive microwaves have recently been arousing greater interest to infer biomass (Ferrazzoli et al., 2002; Rahmoune et al., 2014; Fan et al., 2019). The lower frequencies of the microwave domain are insensitive to atmosphere, cloud, and solar insolation, which allow biomass monitoring at coarse spatial resolution but at high temporal frequency. A strong synergy was found between K-band $(18.7 \mathrm{GHz})$ vegetation optical depth (K-VOD) from AMSR-E satellite and traditional vegetation indices (NDVI, EVI, LAI) time series (Jones et al., 2011). Cband $(6.9 \mathrm{GHz})$ and X-band $(10.7 \mathrm{GHz})$ VOD (C-VOD and X-VOD) from AMSR-E satellite have been used to monitor the evolution of aboveground biomass carbon (Liu et al., 2015). Teubner et al. (2018) showed that VOD at various frequencies was highly correlated to gross primary production (GPP) all over the world. The low frequency L-band (1.4 GHz) VOD (L-VOD) measured with SMOS satellite was also proven to be highly sensitive to aboveground biomass (AGB) in Africa, with less saturation over dense forests than optical indices and than C- or X-VOD (Rodríguez-Fernández et al., 2018). A strong correlation was found between L-VOD and four AGB datasets $(R=0.85-0.94)$. These results were extended to the tropical range in Vittucci et al. (2019) and to the global scale in Mialon et al. (2020). A strong correlation was found at the global scale between L-VOD and two AGB datasets $(R=0.91-0.94)$, but was shown to be highly dependent on the vegetation type.

\footnotetext{
* Corresponding author.

E-mail address: emma.bousquet@cesbio.cnes.fr (E. Bousquet).
} 
VOD at microwave wavelengths is related to vegetation structure and to vegetation water content (VWC, $\mathrm{kg} \mathrm{m}^{-2}$ ) (Jackson and Schmugge, 1991). Therefore, VOD seasonality is predominantly linked to water availability in soil, following the pulse-reserve paradigm (Noy-Meir, 1973) in which rainfall triggers pulses of plant growth and reserves of carbon and energy. Hence, the seasonal cycles of L-VOD and soil moisture (SM) are synchronous over large regions of the globe (Tian et al., 2018; Vittucci et al., 2018).

Nevertheless, in some regions, VOD time series show a phase opposition with water in soil (SM, terrestrial water storage TWS) and with optical vegetation indices (LAI, EVI). Phenological explanations were provided for the specific case of the Miombo woodlands, which could show high VWC and VOD during the dry season due to their deep roots (Tian et al., 2018). In the Amazon rainforest, Jones et al. (2014) showed that the vegetation was more light-adapted than water-adapted, meaning that its seasonal cycle was more controlled by solar insolation than by water availability. Over seasonally inundated regions, a phase opposition was also reported between VOD, water fraction, EVI and GPP (Jones et al., 2011; Teubner et al., 2018), with no plausible phenological explanation. Jones et al. (2011) suggested that the strong decline in AMSR-E K-VOD during flooding could be an artefact due to the presence of vertically-oriented vegetation over a highly reflective water surface. Flooded areas clearly impact passive microwave observations (Ye et al., 2015), allowing Du et al. (2017) to derive a water fraction from AMSR-E and AMSR-2 brightness temperatures. Floods can also impact the retrieval of SM. At L-band, a 1\% underestimation of standing water fraction could induce approximately $0.01 \mathrm{~m}^{3} \mathrm{~m}^{-3} \mathrm{SM}$ retrieval error, for initial conditions ( $\mathrm{SM}=0.4 \mathrm{~m}^{3} \mathrm{~m}^{-3}$, L-VOD =0.6) (Kerr et al., 2020). Since then, several authors filtered out swamps and seasonal wetlands for VOD surveys (Tian et al., 2018). Temporary flooding affects 4\% of the Earth's land surface and are spread all over the globe (Prigent et al., 2019). Their impact on passive microwave estimates may be substantial.

The aim of this study is then to investigate the retrieval of L-VOD over flooded areas. To assess the possible causes of the significant variations in VOD, we examined the seasonal evolution of SMOS L-VOD, AMSR-2C- and X-VOD, with respect to several variables driving the vegetation cycle (LAI, SM, TWS, and water fraction). Then, we modelled the passive microwave retrieval of SM and L-VOD over an inundated landscape, in order to observe whether the retrieved L-VOD could be impacted by dynamic surface water extent. The purpose is to explain the apparent cycle of VOD in seasonally inundated areas, in order to improve passive microwave biomass estimates.

\section{Data}

\subsection{Study area}

The study was conducted at the global scale with the exception of areas covered with snow or ice in winter, which can interfere with Lband observations. A particular focus was drawn on an herbaceous wetland, the Pantanal; on a flooded forest, the Rio Pastaza floodplain; and on a temperate flooded cropland, the lower Mississippi River floodplain (Fig. 1).

The Brazilian Pantanal is the world's largest wetland (Gonçalves et al., 2011), located between 16 and $20^{\circ} \mathrm{S}$ and $56-58^{\circ} \mathrm{W}$. The average annual temperature varies between $22.5^{\circ} \mathrm{C}$ and $26.5^{\circ} \mathrm{C}$. The average precipitation in the basin is $1396 \mathrm{~mm} \mathrm{y}^{-1}$. Heavy rainfall occur during the rainy season, from October to April. Flooding occurs later, between March and July, due to an overflow of the Upper Paraguay River. The Pantanal acts as a reservoir, retaining the waters originated from the surrounding plateau, and regularising the flow of Paraguay River during up to five months (Gonçalves et al., 2011). The area is dominated by waterlogged grasslands, sparse aquatic vegetation, and a thin riparian forest along channels (Ivory et al., 2019).

In contrast, the lower part of the Rio Pastaza floodplain is covered with dense forest regularly flooded. The area is located in the Peruvian Amazon rainforest $\left(3.5-5^{\circ} \mathrm{S}, 76.4-76.6^{\circ} \mathrm{W}\right)$. The average rainfall is 2579 $\mathrm{mm} \mathrm{y}^{-1}$ and is distributed evenly throughout the year. The average annual water discharge at the middle part of the Rio Pastaza is $910 \mathrm{~m}^{3}$ $\mathrm{s}^{-1}$, with the highest discharge in May $\left(1222 \mathrm{~m}^{3} \mathrm{~s}^{-1}\right)$ and the lowest in September $\left(674 \mathrm{~m}^{3} \mathrm{~s}^{-1}\right)$. At high water stage, the entire floodplain is covered by water (Bernal et al., 2013).

Finally, the temperate lower Mississippi River floodplain (USA) contains the third largest drainage basin in the world and gathers the

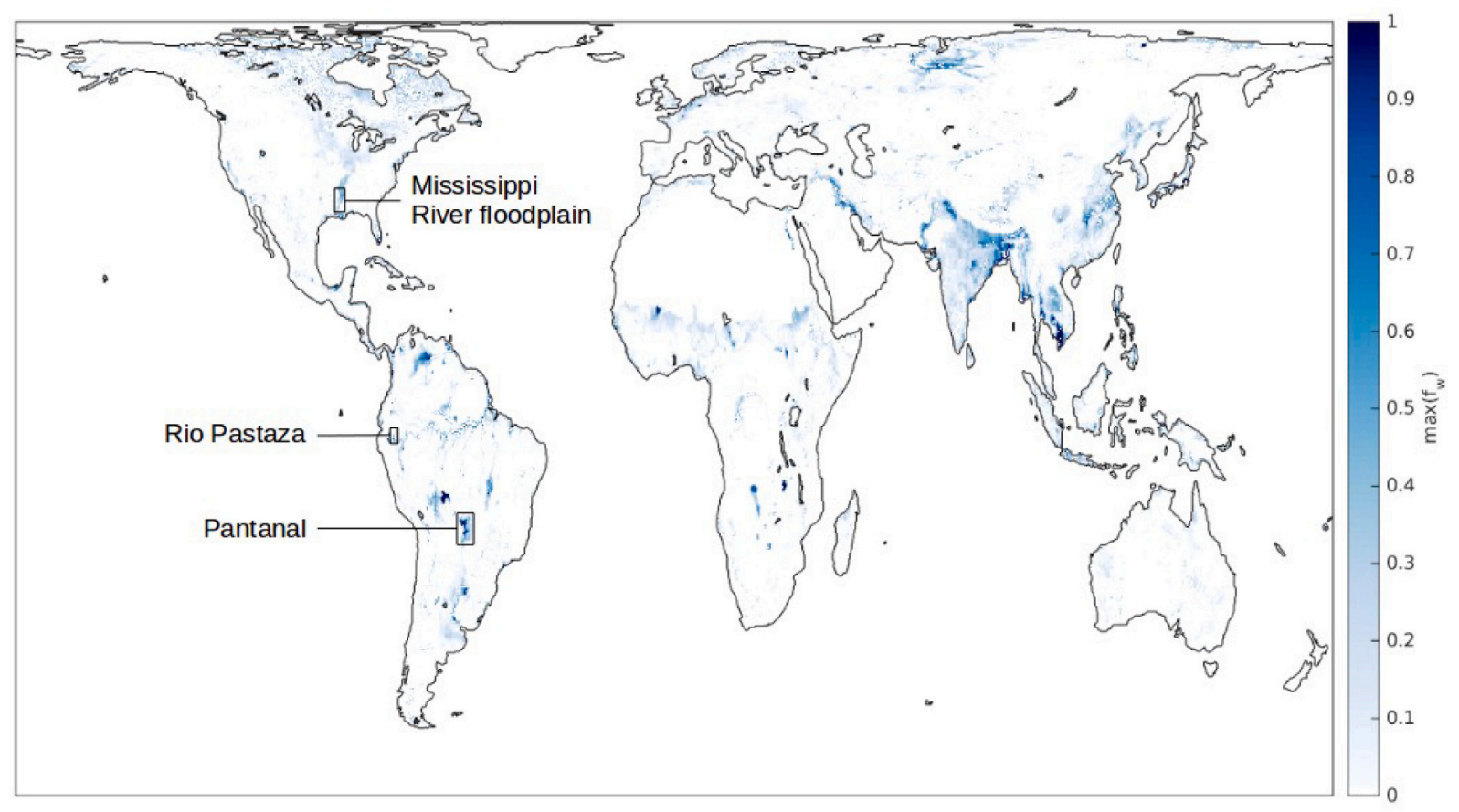

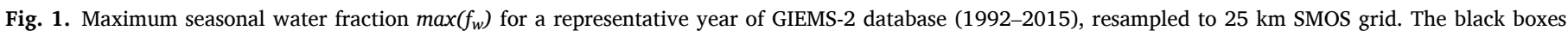
indicate the location of the three study areas. 
flow of many tributaries (Piazza et al., 2015). The studied part spreads from Greenville, Mississippi, to Memphis, Tennessee (33.3-35.2 ${ }^{\circ} \mathrm{N}$, $90.1-91.4^{\circ} \mathrm{W}$ ), and is mostly covered with agricultural parcels.

\subsection{SMOS data}

The SMOS (Soil Moisture and Ocean Salinity) satellite (Kerr et al., 2001) was launched by ESA in 2009. It performs passive measurements of the thermal emission of the Earth at $1.4 \mathrm{GHz}$ in full-polarization, for incidence angles ranging from 0 to $\sim 60 \mathrm{deg}$. The footprint size varies from $\sim 25 \mathrm{~km}$ to $\sim 50 \mathrm{~km}$ depending on the position within the field of view and is $\sim 43 \mathrm{~km}$ in average (Kerr et al., 2010). The equator overpass times are 6:00 and 18:00 for ascending and descending orbits respectively. L-band vegetation optical depth (L-VOD) and soil moisture (SM) are derived from SMOS brightness temperatures $\left(\mathrm{T}_{\mathrm{B}}\right)$ using the L-MEB (L-band Microwave Emission of the Biosphere) radiative transfer model (Wigneron et al., 2007; Kerr et al., 2012), based on the $\tau-\omega$ parameterization (Mo et al., 1982). The vegetation attenuation is taken into account in the $\tau$ parameter of the model, also known as L-VOD. It is related to the vegetation water content (VWC) of woody elements, such as trunks, stems, and branches. The single scattering albedo $\omega$ is used to parametrize the scattering effects within the canopy layer. L-band SM is the volume of water per volume $\left(\mathrm{m}^{3} \mathrm{~m}^{-3}\right)$ of the top surface soil layer $(\sim$ $5 \mathrm{~cm}$ ). The effects of SM and L-VOD can be disentangled using the multiangular and dual-polarization $\mathrm{T}_{\mathrm{B}}$ measurements. SM and L-VOD are retrieved simultaneously by minimizing the differences between the measured and simulated brightness temperatures for different incidence angles (Kerr et al., 2012). The accuracy of the measured brightness temperatures is $3 \mathrm{~K}$ at $300 \mathrm{~K}$ in average (McMullan et al., 2008). SM and L-VOD used here were derived from SMOS-INRA-CESBIO (SMOS-IC) retrieval algorithm (Fernandez-Moran et al., 2017) version 105. SMOSIC also uses the L-MEB as radiative transfer model, but is a simplified version of SMOS Level 2 and Level 3 products, as it considers the footprint homogeneous in terms of land cover. Footprints permanently covered with more than $20 \%$ of open water according to MODIS land cover (Broxton et al., 2014) are excluded, but smaller water bodies and surface water dynamics are currently not taken into account by SMOS-IC algorithm. SMOS-IC dataset is computed on the global cylindrical EqualArea Scalable Earth (EASE) Grid version 2 (Brodzik et al., 2012) with a grid resolution of $625 \mathrm{~km}^{2}(25 \mathrm{~km} \times 25 \mathrm{~km}$ at $30 \mathrm{deg}$. of latitude). Data from June 2010 to December 2019 were used. The commissioning phase of the satellite (before June 2010) was not considered here. Monthly averages were computed with both ascending and descending overpasses, and radio frequency interferences (RFI) areas were excluded, based on the RMSE between modelled $\mathrm{T}_{\mathrm{B}}$ and SMOS $\mathrm{T}_{\mathrm{B}}$ (RMSE $<6 \mathrm{~K}$, Fernandez-Moran et al., 2017).

\subsection{AMSR-2 data}

In order to compare SMOS L-band data to passive microwave data at other frequencies, we also considered AMSR-2 VOD dataset (Imaoka et al., 2010). As part of JAXA Global Change Observation Mission (GCOM), AMSR-2 radiometer succeeded in 2012 to AMSR-E NASA's Aqua satellite (Kawanishi et al., 2003). Two frequencies were considered: $6.9 \mathrm{GHz}$ and $10.7 \mathrm{GHz}$, corresponding to $\mathrm{C} 1$ - and X-bands respectively. C2-band $(7.3 \mathrm{GHz})$ was not discussed in this paper as the data were mostly redundant with C1-band. We used the daily L3 V001 VOD products, processed with LPRM algorithm (Owe et al., 2008) and distributed by NASA in a regular grid at $25 \mathrm{~km} \times 25 \mathrm{~km}$ resolution. We computed monthly averages of merged ascending and descending overpasses (LPRM_AMSR2_A_SOILM3 and LPRM_AMSR2_D_SOILM3), from July 2012 to December 2019. VOD measured at these higher frequencies is sensitive to stems and leaves of the top canopy surface.

\subsection{GIEMS-2 dataset}

Seasonally inundated areas were located with GIEMS-2 dataset (Prigent et al., 2019), a new version of the Global Inundation Estimate from Multiple Satellites (GIEMS, Prigent et al., 2001). It provides a longterm global map of surface water extent by merging passive, active, visible and near-infrared data (SSM/I, ERS, AVHRR). The water fraction $\mathrm{f}_{\mathrm{w}}$ is delivered at a monthly time-scale from 1992 to 2015, on an equal area grid of $0.25 \mathrm{deg} . \times 0.25 \mathrm{deg}$. at the equator $(\sim 25 \mathrm{~km})$. The maximum water fraction $\max \left(f_{w}\right)$ over a representative year for the period 1992-2015 is shown in Fig. 1. In this updated product, the estimation of microwave emissivity is less dependent on ancillary data, and the final water surface estimation was corrected of a known overestimation over low vegetation areas. GIEMS-2 inundated extension showed good agreement with precipitation estimates and altimeter river height (Prigent et al., 2019). $\mathrm{f}_{\mathrm{w}}$ errors were estimated to represent $\sim 10 \%$ of the pixel surface (Prigent et al., 2007). Though current GIEMS-2 estimates were only available until 2015 , we considered the seasonal evolution of water fractions to be representative of the studied period (2010-2019) at the $25 \mathrm{~km}$ scale.

\subsection{GRACE terrestrial water storage}

SMOS top surface layer soil moisture (SM) was compared with terrestrial water storage (TWS) anomalies from GRACE satellite. We used monthly GRACE/GRACE-FO Level-3 product provided by GFZ web portal GravIS at $1 \mathrm{deg}$. latitude-longitude grids (Boergens et al., 2019). TWS anomalies represent the temporal changes in the Earth's gravity field over the continents, interpreted in terms of changes in the terrestrially stored water masses including snow, surface water, soil moisture, and deep groundwater. 35 months were occasionally missing in the tenyear period. One-month gaps were filled by linear interpolation, and consecutive missing months were not considered. As SMOS only accounts for the water of the top soil layer $(\sim 5 \mathrm{~cm}$, Escorihuela et al., 2007), a time lag is expected between SMOS SM and GRACE TWS time series, depending on the type of soil.

\subsection{PROBA-V leaf area index}

Leaf area index (LAI) data were also considered in order to monitor the vegetation emergence cycle. We used ESA PROBA-V satellite dataset in version 2 (Verger et al., 2014), distributed at $1 \mathrm{~km}$ resolution each 10 days by Copernicus Global Land Service. LAI is defined as half the total area of green elements of the canopy per unit horizontal ground area, and is expressed in $\mathrm{m}^{2} \mathrm{~m}^{-2}$. The satellite-derived value is obtained from the red and near infrared channels. Contrary to L-VOD, LAI is sensitive to the leave chlorophyll content but is independent of woody elements. Satellite LAI is widely used to monitor vegetation, but suffers from a fast saturation over dense vegetation, as only the canopy surface is observed; and cannot be obtained under cloudy conditions, which occurs frequently. Moreover, LAI can be artificially increased during flooding due to a strong water absorption misinterpreted as a denser canopy (Fuster et al., 2020). Nevertheless, this overestimation remains limited (+0.4-0.7 $\mathrm{m}^{2} \mathrm{~m}^{-2}$ found by Campos-Taberner et al., 2018) and disappears when canopy closure increases, since optical measurements cannot penetrate the surface layer.

\subsection{MODIS Land cover}

A land surface climatology map based on 10 years (2001-2010) of the MODIS MCD12Q1 product at $500 \mathrm{~m}$ resolution (Broxton et al., 2014) is used in SMOS-IC algorithm to exclude large water bodies (see Sect. SMOS data), and was also used in this study to filter the data (see Section 3). This land cover identifies 17 ecosystems based on IGBP (International Geosphere-Biosphere Programme) class labels (Table 4). 


\subsection{Snow and ice database}

The Interactive Multisensor Snow and Ice Mapping System (IMS) database was used to mask areas covered with snow or ice for at least one month per year (see Section 3). We used the IMS Daily Northern Hemisphere Snow and Ice Analysis at $4 \mathrm{~km}$ resolution, version 1 (Helfrich et al., 2007), provided by the National Snow and Ice Data Center (NSIDC).

\section{Methods}

\subsection{Satellite data processing}

The study was conducted from June 2010 to December 2019, even though AMSR-2 dataset starts in July 2012, and GIEMS-2 dataset ends in December 2015. Monthly averages were computed in order to remove daily variability and to focus on seasonal patterns. All datasets were resampled to SMOS EASE-Grid 2 with gdal (GDAL/OGR contributors, 2020). The high-resolution LAI product ( $1 \mathrm{~km}$ ) was averaged to the SMOS grid. The $500 \mathrm{~m}$ resolution land cover map and the $4 \mathrm{~km}$ resolution IMS database were resampled by allocating the dominant class for each pixel. A nearest neighbour resampling method was applied to the coarse resolution datasets (AMSR-2C- and X-VOD, GIEMS-2 $f_{w}$, GRACE TWS).

The Pearson correlation coefficient map between SMOS-IC L-VOD and SM anomalies was computed in order to highlight areas where a significant increase (resp. decrease) in SM is linked to a decrease (resp. increase) in L-VOD, such that $\mathrm{R} \sim-1$. The anomalies of L-VOD (resp. SM) were computed with the difference between L-VOD (resp. SM) time series and a so called "representative year", computed with an average month per month over the 2010-2019 period. Regions affected by RFI were excluded (see Section 2), as well as barren, urban, snow and ice land cover (IGBP classes 13, 15, and 16), and areas covered with snow or ice for at least one month per year, based on the IMS product.

The L-VOD seasonal amplitude was computed in flooded and nonflooded areas, in order to observe the magnitude of the impact of flooding on L-VOD values. The L-VOD seasonal amplitude is the difference between maximum and minimum L-VOD values of the afore mentioned representative year. Flooded areas were defined as $\max \left(f_{w}\right)-$ $\min \left(f_{w}\right) \geq 0.1$; and non-flooded areas as $\max \left(f_{w}\right)-\min \left(f_{w}\right)=0, \mathrm{f}_{\mathrm{w}}$ being GIEMS-2 water fraction seasonality over the 2010-2015 period.

A particular attention was then dedicated to the Pantanal, the Rio Pastaza and the Mississipi River floodplains as cases of study, where monthly time series of all data were observed over the ten-year period and over a representative year.

\subsection{Modelling experiment}

\subsubsection{Rationale}

SMOS-IC algorithm considers the scene homogeneous in terms of land cover and proceeds the retrieval without removing the contribution of open water. Note that pixels covered with more than $20 \%$ of open water are excluded from the retrieval (see Sect. SMOS data). The aim of this section is to evaluate the uncertainties introduced in the derived SM and L-VOD by assuming the soil to be homogeneous whereas in reality, a fraction of open water may exist and vary temporally. For that purpose, a three-step modelling experiment was conducted as follows (Fig. 2):

1) Simulation of a brightness temperature $\left(T_{B \text { mix }}\right)$ for a scene under heterogeneous land cover conditions, i.e. with an open water fraction $\left(f_{w}\right)$. The soil moisture value on the soil fraction $\left(f_{s}\right)$ is called $S_{\mathrm{s}}$. A vegetation layer is considered above soil $\left(\tau_{s}\right)$, and possibly above water $\left(\tau_{\mathrm{w}}\right)$.

2) Retrieval of SM $\left(\mathrm{SM}_{\mathrm{r}}\right)$ and L-VOD $\left(\tau_{\mathrm{r}}\right)$ using $\mathrm{T}_{\mathrm{Bmix}}$ computed in step 1 and SMOS-IC algorithm, which assumes the scene to be homogeneous.

3) Evaluation of the differences between the retrieved couple $\left(\mathrm{SM}_{\mathrm{r}}, \tau_{\mathrm{r}}\right)$ and the initial couple $\left(\mathrm{SM}_{\mathrm{s}}, \tau_{\mathrm{s}}\right)$.

\subsubsection{Description of the model and of the parameters}

We considered a mixed pixel consisting of dynamic fractions of soil $\left(f_{s}\right)$ and of water $\left(f_{w}\right)$, such as $f_{w}+f_{s}=1$. A vegetation layer can be added to both surfaces, with the $\tau$ parameter of the model and possibly different values above soil $\left(\tau_{\mathrm{s}}\right)$ and above water $\left(\tau_{\mathrm{w}}\right)$ (Fig. 3 ). The radiative model used to simulate $\mathrm{T}_{\mathrm{Bmix}}$ (step 1) and to perform the retrieval (step 2) is the L-MEB model (Wigneron et al., 2007), as in SMOS-IC algorithm. Several simulation parameters are reported here and in Tables 1 and 2. A review of the equations and their associated parameters is fully described in Fernandez-Moran et al. (2017).

- the soil moisture value on the soil fraction $\left(\mathrm{SM}_{\mathrm{s}}, \mathrm{m}^{3} \mathrm{~m}^{-3}\right)$;

- the vegetation optical depth value on the soil fraction $\left(\tau_{\mathrm{s}}\right)$ and on the water fraction $\left(\tau_{\mathrm{w}}\right)$;

- the vegetation single scattering albedo $(\omega)$ for the $\tau$ - $\omega$ model (Mo et al., 1982);

- the clay and sand fractions ( $\mathrm{f}_{\text {clay }}$ and $\mathrm{f}_{\text {sand }}$, such that $\mathrm{f}_{\text {clay }}+\mathrm{f}_{\text {sand }}=1$ ) for the Mironov dielectric constant of the soil;

- the soil roughness parameters $\mathrm{H}_{\mathrm{R}}, \mathrm{Q}_{\mathrm{R}}, \mathrm{N}_{\mathrm{RH}}, \mathrm{N}_{\mathrm{RV}}$ (Wang and Choudhury, 1981; Wigneron et al., 2001);

- the soil, air and water temperatures $\mathrm{T}_{\mathrm{s}}, \mathrm{T}_{\mathrm{air}}$ and $\mathrm{T}_{\mathrm{w}}$.

The influence of soil texture, surface roughness, and temperature was analysed and did not show significantly different results from the ones presented here. We considered the same values for all tests (Table 2).

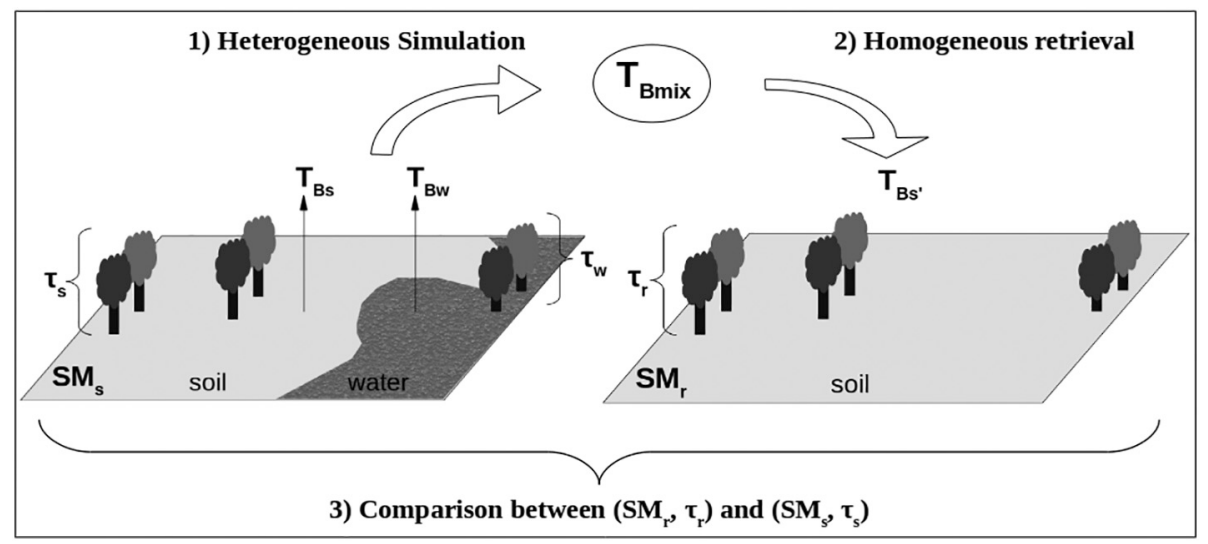

Fig. 2. Flowchart of the modelling experiment. $\mathrm{TB}_{\text {mix }}$ is computed using Eq. (1). 

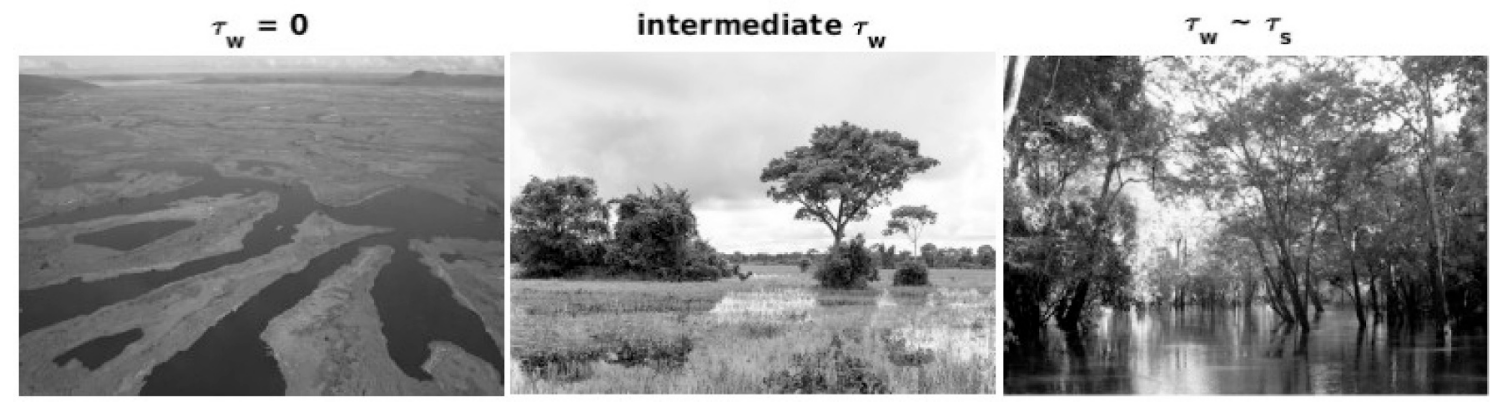

Fig. 3. Examples of real landscapes to illustrate $\tau_{\mathrm{w}}$ value (vegetation optical depth above standing water). Left: most wetlands are totally submerged during flooding, without emerging vegetation $\left(\tau_{\mathrm{w}}=0\right)$. Centre: aquatic vegetation forms and some shrubs remain above water (intermediate $\tau_{\mathrm{w}}$ ). Right: in flooded forests, the major part of the vegetation remains above water $\left(\tau_{\mathrm{w}} \sim \tau_{\mathrm{s}}\right)$. Copyrights Carl de Souza, AFP, Brazil Selection, Mongabay.

Table 1

Values of the main parameters used in the model.

\begin{tabular}{|c|c|c|c|c|c|}
\hline & & $f_{w}$ & $\mathrm{SM}_{\mathrm{s}}$ & $\tau_{s}$ & $\tau_{\mathrm{w}}$ \\
\hline Case A - Theoretical study & & 0:0.01:1 & 0.1:0.1:0.6 & $0.2: 0.2: 1.2$ & $0, \tau_{\mathrm{s}} / 2, \tau_{\mathrm{s}}$ \\
\hline \multirow[t]{2}{*}{ Case B - Regional study } & - Pantanal & GIEMS- $2 \mathrm{f}_{\mathrm{w}}$ & SMOS SM & $\max ($ SMOS L-VOD) & $0.3 \times \tau_{\mathrm{s}}$ \\
\hline & - Rio Pastaza & “ & “ & “ & $0.9 \times \tau_{\mathrm{s}}$ \\
\hline
\end{tabular}

\subsubsection{Step 1: Computation of the brightness temperatures}

The brightness temperatures of the mixed pixel $\mathrm{T}_{\mathrm{Bmix}}(\mathrm{K})$ were simulated for incidence angles ranging from 0 to $55 \mathrm{deg}$. with $5 \mathrm{deg}$. step, following Eq. (1) (step 1 in Fig. 2):

$T_{B m i x}=f_{w} \times T_{B w}\left(\tau_{w}\right)+\left(1-f_{w}\right) \times T_{B s}\left(S M_{s}, \tau_{s}\right)$

where $\mathrm{T}_{\mathrm{Bs}}$ and $\mathrm{T}_{\mathrm{Bw}}$ stand for the brightness temperatures of soil and water respectively. $T_{B s}$ was computed using the model described in Section 3.2.2. $\mathrm{T}_{\mathrm{Bw}}$ was computed using the emissivity determined by the dielectric constant of water (Ulaby et al., 1981; Klein and Swift, 1977) multiplied by its temperature $\mathrm{T}_{\mathrm{w}}$, set to $20^{\circ} \mathrm{C}$ (Table 1 ).

\subsubsection{Step 2: $S M / \tau$ retrieval}

In step $2, \mathrm{SM}_{\mathrm{r}} / \tau_{\mathrm{r}}$ retrieval was performed assuming that the pixel was homogeneous and only composed of soil, with a brightness temperature $\mathrm{T}_{\mathrm{Bs}}$ ' (Fig. 2):

$T_{B m i x}=T_{B s^{\prime}}\left(S M_{r}, \tau_{r}\right)$

The retrieval was computed with SMOS-IC algorithm, which performs a minimization of the cost function computed from the quadratic differences between modelled brightness temperatures $\mathrm{T}_{\mathrm{Bmix}}$ and $\mathrm{T}_{\mathrm{Bs}}$, for various incidence angles $(\theta)$, in order to retrieve simultaneously the soil moisture $\left(\mathrm{SM}_{\mathrm{r}}\right)$ and the vegetation optical thickness $\left(\tau_{\mathrm{r}}\right)$. The cost function CF was computed as in SMOS (Wigneron et al., 2001; Kerr et al., 2012):

$C F=\frac{\sum\left(T_{B m i x}(\theta)-T_{B s^{\prime}}(\theta)\right)^{2}}{\sigma\left(T_{B}\right) 2}+\sum_{i} \frac{\sum\left(P_{i}^{i n i}-P_{i}^{r}\right) 2}{\sigma\left(P_{i}\right) 2}$

In which both polarizations and all available angles were used. $\sigma\left(\mathrm{T}_{\mathrm{B}}\right)$ is the radiometric accuracy associated with the brightness temperature measurements, set to $3 \mathrm{~K}$ at $300 \mathrm{~K}$ (McMullan et al., 2008); $\mathrm{P}_{\mathrm{i}}^{\mathrm{r}}(\mathrm{i} \in[1 ; 2])$ is the value of the retrieved parameters $\left(\mathrm{SM}_{\mathrm{r}}, \tau_{\mathrm{r}}\right)$; $\mathrm{P}_{\mathrm{i}}^{\mathrm{ini}}(\mathrm{i} \in[1 ; 2])$ is the initial value of the free parameters; and $\sigma\left(\mathrm{P}_{\mathrm{i}}\right)$ is the uncertainty associated with these free parameters, fixed to 0.3 on SM and $\tau$. SM impacts mostly the level of the brightness temperatures, i.e. $T_{B}$ decrease with increasing soil moisture; whereas $\tau$ impacts the difference between the two polarizations $T_{B h}$ and $T_{B v}$. The difference $T_{B h}-T_{B v}$ decreases when $\tau$ increases, because the vegetation cover induces a depolarization of the signal.

3.2.4.1. Case A. Comprehensive study with theoretical values. A large range of $\left(\mathrm{SM}_{s}, \tau_{\mathrm{s}}\right)$ values was first tested (Table 1$)$, and the water fraction $\mathrm{f}_{\mathrm{w}}$ varied between 0 and 1 by increments of 0.01 . Three cases were considered for $\tau_{\mathrm{w}}$ : no vegetation above water $\left(\tau_{\mathrm{w}}=0\right)$, sparse vegetation above water $\left(\tau_{\mathrm{w}}=\tau_{\mathrm{s}} / 2\right)$, and same amount of vegetation above water as above soil $\left(\tau_{\mathrm{w}}=\tau_{\mathrm{s}}\right)$. These cases are illustrated in Fig. 3 .

3.2.4.2. Case B. Region based study over a representative year. To illustrate more realistic situations, we also modelled the retrieval over a representative year in the three study areas. For that purpose, we considered $\mathrm{f}_{\mathrm{w}}$ from GIEMS-2 seasonality, $\mathrm{SM}_{\mathrm{s}}$ from SMOS-IC SM seasonality, and $\tau_{\mathrm{s}}$ from the maximum value of SMOS-IC L-VOD seasonality (Table 1), which is its value during the minimum flooding. Though not entirely accurate, the hypothesis of a constant $\tau_{\mathrm{s}}$ value throughout the year enables to observe only the impact of water, and is justified by a low L-VOD seasonal amplitude is over grasslands and evergreen broadleaf forests (Table 4). $\tau_{\mathrm{w}}$ value is difficult to estimate as it depends on the vegetation height and on the water depth. During flooding, the Pantanal wetland is mostly covered with herbaceous swamps and sparse aquatic vegetation (Ivory et al., 2019). The vegetation amount above water was estimated to $30 \%$ of the vegetation amount above soil $\left(\tau_{\mathrm{w}}=0.3 \times \tau_{\mathrm{s}}\right)$. The same value was considered for the lower Mississippi River floodplain, predominantly covered with croplands. In contrast, the Rio

Table 2

Values of the secondary parameters used in the model (same for Cases A, B, C).

\begin{tabular}{|c|c|c|c|c|c|c|c|c|c|}
\hline$\omega$ & $\mathrm{f}_{\text {clay }}$ & $\mathrm{f}_{\text {sand }}$ & $\mathrm{H}_{\mathrm{R}}$ & $\mathrm{Q}_{\mathrm{R}}$ & $\mathrm{N}_{\mathrm{RH}}$ & $\mathrm{N}_{\mathrm{RV}}$ & $\mathrm{T}_{\mathrm{s}}=\mathrm{T}_{\mathrm{air}}=\mathrm{T}_{\text {canopy }}$ & $\mathrm{T}_{\mathrm{s} \text { prof }}$ & $\mathrm{T}_{\mathrm{w}}$ \\
\hline 0.08 & 0.35 & 0.65 & 0.1 & 0 & -1 & -1 & $25^{\circ} \mathrm{C}$ & $18^{\circ} \mathrm{C}$ & $20^{\circ} \mathrm{C}$ \\
\hline
\end{tabular}


Pastaza floodplain is densely forested (Bernal et al., 2013) and only the understorey is submerged under water (Kalliola et al., 1991). We considered that $90 \%$ of the vegetation amount above soil remained above water during flooding $\left(\tau_{\mathrm{w}}=0.9 \times \tau_{\mathrm{s}}\right)$. The initial parameters and the retrieval were computed pixel by pixel in each area (180 pixels for the Pantanal, 18 pixels for the Rio Pastaza, 54 pixels for the Mississippi River floodplain, black boxes in Fig. 1), and the results were eventually averaged.

3.2.4.3. Case C. Global study. The previous experiment was extended to the global scale, except for barren, urban, snow and ice land covers and snow-covered areas in winter (IMS database) in order to avoid misleading conclusions linked to the presence of snow or melting snow. For Case $\mathrm{C}$, the water fraction $\mathrm{f}_{\mathrm{w}}$ was the sum of GIEMS- 2 seasonality and permanent water bodies from MODIS land cover (percentage of IGBP class 0 ). Indeed, permanent water bodies smaller than $20 \%$ of the pixel surface (lakes, rivers or coastal areas) are conserved in SMOS-IC retrieval and can impact SM and L-VOD retrieval throughout the year. As in Case B, $\mathrm{SM}_{\mathrm{s}}$ was from SMOS-IC SM seasonality and $\tau_{\mathrm{s}}$ from the maximum value of SMOS-IC L-VOD seasonality. At the global scale, this consideration is less reliable as L-VOD can vary significantly in some areas, due to the vegetation seasonal cycle (Table 4). The vegetation amount above water $\tau_{\mathrm{w}}$ was adapted to the land cover. We considered high values of $0.8 \times \tau_{\mathrm{s}}$ for forest classes (IGBP classes $\left.1,2,3,4,5\right)$ ) $0.4 \times$ $\tau_{\mathrm{s}}$ for intermediate vegetation (IGBP classes $6,7,8,9,12,14$ ); and 0 for low vegetation and permanent water bodies (IGBP classes $0,10,11$ ). All of these considerations are highly simplified and only aim to provide an order of magnitude of the global impact of surface water on L-VOD observations for a representative year. L-VOD error was computed with the difference between $\tau_{\mathrm{r}}$ and $\tau_{\mathrm{s}}$.

\subsection{Impact on the aboveground biomass (AGB) estimation}

L-VOD was recently found to be very sensitive to aboveground biomass (AGB) (Rodríguez-Fernández et al., 2018; Vittucci et al., 2019) and has been used as a proxy for monitoring AGB and aboveground carbon (AGC) evolution (Brandt et al., 2018; Fan et al., 2019; Wigneron et al., 2020). L-VOD measurement errors due to standing water could impact the derived AGB values. In order to quantify this impact, the global ten-year average SMOS-IC L-VOD and its corrected value LVOD $_{\text {corr }}$ estimated with the yearly average error in L-VOD (Case C) were converted into $\mathrm{AGB}_{\text {ini }}$ and $\mathrm{AGB}_{\text {corr }}$ using the fitting function from Rodríguez-Fernández et al. (2018):

$A G B=\frac{a}{1+e^{-b(L V O D-c)}}+d$

The parameters $a, b, c, d$ were determined for SMOS-IC L-VOD by Rodríguez-Fernández et al. (2018) with respect to four different AGB datasets. We considered the parameter values provided in Table 3 computed with Baccini AGB dataset (Baccini et al., 2012) as the Pearson correlation coefficient was the highest found $(R=0.94, \rho=0.90)$. The error on $\mathrm{AGB}$ was computed with the difference between $\mathrm{AGB}_{\text {ini }}$ and $\mathrm{AGB}_{\text {corr. }}$.

Table 3

Parameters of the fits of Baccini AGB vs SMOS-IC L-VOD used in Eq. (4), from Rodríguez-Fernández et al. (2018).

\begin{tabular}{lllll}
\hline curve & $\mathrm{a}\left(\mathrm{Mg} \mathrm{ha}^{-1}\right)$ & $\mathrm{b}$ & $\mathrm{c}$ & $\mathrm{d}\left(\mathrm{Mg} \mathrm{ha}^{-1}\right)$ \\
\hline 5th percentile & 455.774 & 2.785 & 0.964 & -40.357 \\
mean & 422.744 & 3.400 & 0.729 & -29.252 \\
95th percentile & 393.863 & 4.685 & 0.558 & -6.444 \\
\hline
\end{tabular}

\section{Results}

\subsection{Satellite observations}

\subsubsection{Correlation map between $L-V O D$ and $S M$ anomalies}

The Pearson correlation coefficient between SMOS-IC L-VOD and SM anomalies is shown at the global scale in Fig. 4. Several areas were filtered out as described in Section 3. A strong anti-correlation between L-VOD and SM anomalies (R close to -1 , red areas) appears over most seasonally inundated areas: the Mississippi River alluvial plain, the Orinoco's drainage basin (Colombia and Venezuela), Rio Branco and Bolivian floodplains (Amazon), the Pantanal, the Rio de la Plata basin (Argentina), Liuwa plains (Zambia), Western India and South-East Asia. The Pearson correlation coefficient is -0.77 in the Pantanal wetland, -0.67 in the Rio Pastaza flooded forest, and -0.84 in the Mississippi River floodplain. L-VOD and SM anomalies are well correlated over most dry regions ( $\mathrm{R}$ close to 1 , blue areas), following the pulse-reserve paradigm (Noy-Meir, 1973).

\subsubsection{L-VOD seasonal amplitude}

The L-VOD seasonal amplitude was computed for each land cover class, in flooded and non-flooded areas (Table 4). Without floods, the most stable vegetation classes are evergreen forests, shrublands, and grasslands $\left(3.910^{-2}-7.710^{-2}\right)$. On the contrary, high seasonal variations of L-VOD occur in croplands, deciduous broadleaf and mixed forests $\left(9.010^{-2}-11.110^{-2}\right)$, due to an intense flourishing and an increase of the biomass amount in spring (Rahmoune et al., 2014). For all classes except mixed forests, L-VOD seasonal amplitude increases with floods. The differences vary from $+8 \%$ in woody savannas to $+56 \%$ in evergreen broadleaf forests and in open shrublands.

\subsubsection{Regional time series}

In order to investigate the links between floods and vegetation cycle, we focused on the three regions described in Section 2. Fig. 5 displays the average seasonality of L-, C-, and X-VOD as well as LAI, $\mathrm{f}_{\mathrm{W}}, \mathrm{SM}$, and TWS over the areas. The water fraction varies seasonally from 0.07 to 0.38 in the Pantanal (Fig. 5a), from 0.04 to 0.21 in the Rio Pastaza forest (Fig. 5b), and from 0.04 to 0.41 in the lower Mississippi River floodplain (Fig. 5c). In the Pantanal (Fig. 5a), the L-VOD seasonal cycle is in good agreement with VOD at higher frequencies (Pearson correlation coefficients of $\mathrm{R}_{\mathrm{L}-\mathrm{VOD}, \mathrm{C}-\mathrm{VOD}}=0.99$ and $\mathrm{R}_{\mathrm{L}-\mathrm{VOD}, \mathrm{X}-\mathrm{VOD}}=1$ ), but shows a lower mean value $(0.29)$ and a lower amplitude $(0.08)$ than $C$ - and $X$ VOD ( 0.55 in average, 0.14 in amplitude). All VOD cycles are asynchronous with LAI, $f_{W}, S M$, and TWS cycles $\left(R_{L-V O D, L A I}=-0.67, R_{L-V O D}\right.$, $\mathrm{fw}=-0.99$, and $\left.\mathrm{R}_{\mathrm{L}-\mathrm{VOD}, \mathrm{SM}}=-0.97\right)$. No phenological explanation can justify why the L-, C- and X-VOD cycles are totally opposite to water availability nor leaf emergence. In the Rio Pastaza tropical dense forest (Fig. 5b), the seasonal cycles of LAI and of X-VOD are low, but L- and CVOD cycles are more marked and opposite to $\mathrm{f}_{\mathrm{w}}, \mathrm{SM}$, and TWS $\left(\mathrm{R}_{\mathrm{L}-\mathrm{VOD}, \mathrm{fw}}\right.$ $=-0.91, \mathrm{R}_{\mathrm{L}-\mathrm{VOD}, \mathrm{SM}}=-0.93$ ). In the Mississippi River floodplain (Fig. $5 c)$, the LAI is in phase with all VOD $\left(\mathrm{R}_{\mathrm{L}-\mathrm{VOD}, \mathrm{LAI}}=0.73\right)$, which are also opposite to $\mathrm{f}_{\mathrm{W}}, \mathrm{SM}$, and TWS $\left(\mathrm{R}_{\mathrm{L}-\mathrm{VOD}, \mathrm{fw}}=-0.97, \mathrm{R}_{\mathrm{L}-\mathrm{VOD}, \mathrm{SM}}=\right.$ $-0.99)$. On Fig. 6 , we plotted the time series of L-VOD, LAI, SM and $f_{w}$ from June 2010 to December 2019 (2015 for $\mathrm{f}_{\mathrm{w}}$ ) over the Pantanal in order to observe the inter-annual variability. The same time series for the two other study areas are provided in Fig. S1. As mentioned above, $\mathrm{SM}$ and $\mathrm{f}_{\mathrm{w}}$ are highly correlated $\left(\mathrm{R}_{\mathrm{SM}, \mathrm{fw}}=0.93\right)$. The LAI follows the same seasonality with less inter-annual variability $\left(\mathrm{R}_{\mathrm{SM}, \mathrm{LAI}}=0.50\right)$. On the contrary, L-VOD variations are negatively correlated to SM and $\mathrm{f}_{\mathrm{w}}$ variations $\left(\mathrm{R}_{\mathrm{L}-\mathrm{VOD}, \mathrm{SM}}=-0.92\right.$ and $\mathrm{R}_{\mathrm{L}-\mathrm{VOD}, \mathrm{fw}}=-0.95$, Fig. $\left.\mathrm{S} 2\right)$. They are particularly marked in 2011, and barely visible in 2012 .

\subsection{Modelling experiment}

The results presented in Section 4.1. suggest that the VOD is linked to the dynamics of floods. Dynamic water extents are currently not taken 


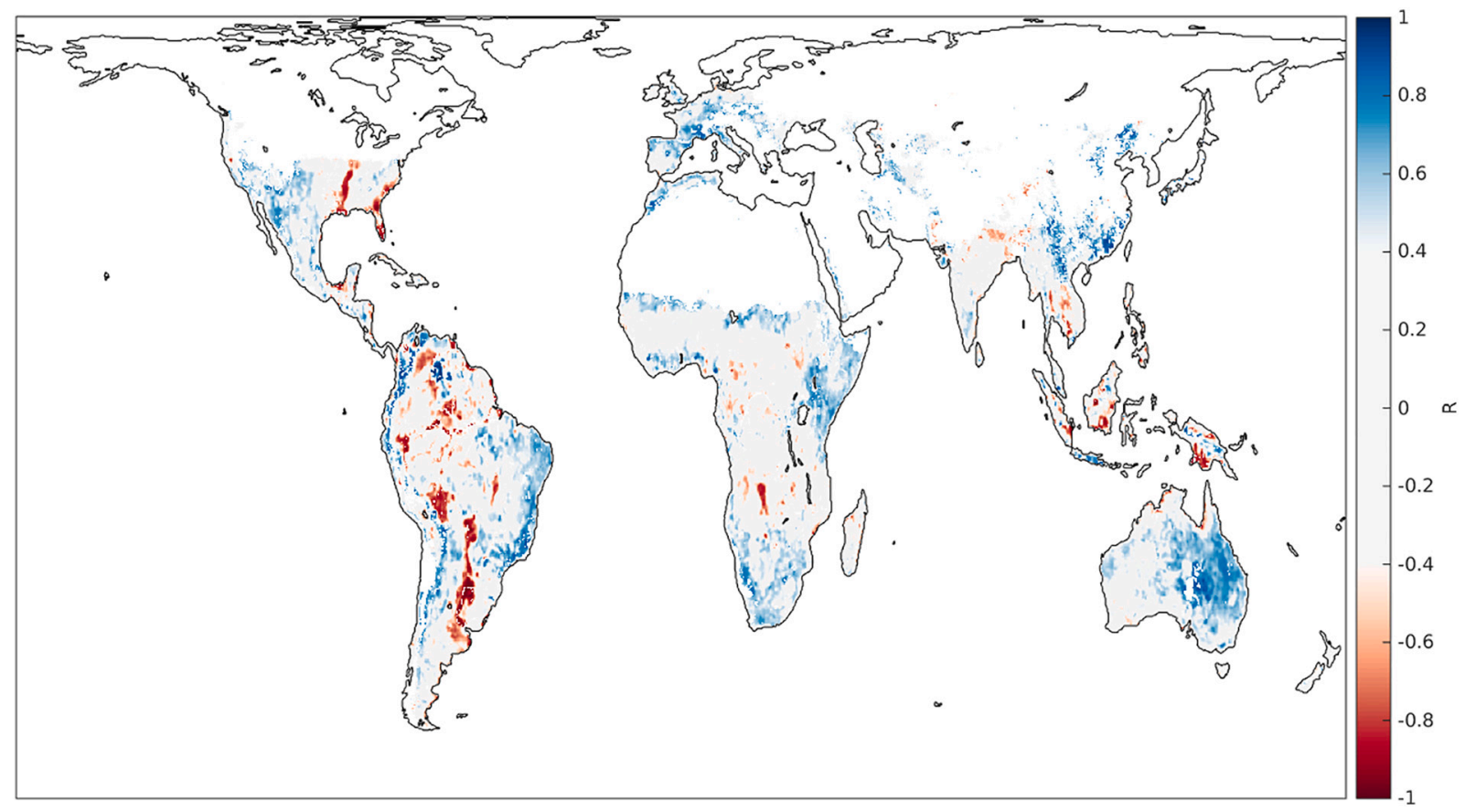

Fig. 4. Pearson correlation coefficient R between SMOS-IC L-VOD and SM anomalies, 2010-2019. RFI areas were filtered out, as well as regions covered with snow in winter, and barren, urban, snow and ice land cover classes.

\section{Table 4}

Seasonal amplitude of L-VOD for each land cover class, flooded and non-flooded areas separately. Land cover classes 0 (water bodies), 11 (permanent wetlands), 13 (urban), 15 (snow and ice) and 16 (barren) were excluded. Land cover class 3 (deciduous needleleaf forests) and flooded areas of classes 1 and 6 were masked due to the temporary presence of snow.

\begin{tabular}{lllll}
\hline $\begin{array}{l}\text { IGBP } \\
\text { label }\end{array}$ & Class & $\begin{array}{l}\text { L-VOD } \\
\text { amplitude, non- } \\
\text { flooded areas }\end{array}$ & $\begin{array}{l}\text { L-VOD } \\
\text { amplitude, } \\
\text { flooded areas }\end{array}$ & Difference \\
\hline 1 & $\begin{array}{l}\text { evergreen } \\
\text { needleleaf forests }\end{array}$ & $5.410^{-2}$ & - & - \\
2 & $\begin{array}{l}\text { evergreen } \\
\text { broadleaf forests }\end{array}$ & $5.110^{-2}$ & $8.010^{-2}$ & $+56 \%$ \\
& deciduous & $10.210^{-2}$ & $11.910^{-2}$ & $+17 \%$ \\
4 & broadleaf forests & & & $-30 \%$ \\
5 & mixed forests & $11.110^{-2}$ & $7.810^{-2}$ & - \\
6 & $\begin{array}{l}\text { closed } \\
\text { shrublands }\end{array}$ & $6.610^{-2}$ & - & $+56 \%$ \\
7 & open shrublands & $3.910^{-2}$ & $6.010^{-2}$ & $+8 \%$ \\
8 & woody savannas & $8.910^{-2}$ & $9.710^{-2}$ & $+49 \%$ \\
10 & savannas & $8.010^{-2}$ & $12.010^{-2}$ & $+15 \%$ \\
12 & $\begin{array}{l}\text { grasslands } \\
\text { croplands }\end{array}$ & $7.710^{-2}$ & $8.810^{-2}$ & $+22 \%$ \\
14 & $\begin{array}{l}\text { cropland/natural } \\
\text { vegetation }\end{array}$ & $8.510^{-2}$ & $11.010^{-2}$ & $+22 \%$ \\
& mosaics & & $10.410^{-2}$ & \\
\hline
\end{tabular}

into account by state of the art SM and VOD retrievals from passive radiometers such as SMOS, SMAP and AMSR-2. The goal of the current section is to analyse how the SM and VOD retrievals are affected by a water fraction not accounted for in the retrieval process.

\subsubsection{Case A. Comprehensive study with theoretical values}

The brightness temperatures simulated over a mixed pixel $\mathrm{T}_{\mathrm{Bmix}}$ are shown on Fig. S3 with increasing water fraction values $\left(f_{w}=0,0.5,1\right)$. As it is well known, brightness temperature values notably decrease when the water fraction increases (Ulaby et al., 1981), leading to an overestimation of the retrieved SM values (Ye et al., 2015). The decrease in brightness temperatures is stronger without vegetation above water
(Fig. S3, left panel). Moreover, the difference $T_{B h}-T_{B v}$ increases with $f_{W}$, certainly leading to $\tau_{\mathrm{r}}$ values lower than $\tau_{\mathrm{s}}$ values. When vegetation remains above water (Fig. S3, right panel), the brightness temperatures level is less impacted, and a specific angular signature appears. The evolution of the difference $\mathrm{T}_{\mathrm{Bh}}-\mathrm{T}_{\mathrm{Bv}}$ is less clear.

The retrieved $\left(\mathrm{SM}_{\mathrm{r}}, \tau_{\mathrm{r}}\right)$ for various initial conditions $\left(\mathrm{SM}_{\mathrm{S}}, \tau_{\mathrm{s}}\right.$, open circles in Fig. 7) and $\tau_{\mathrm{w}}$ cases are presented in Fig. 7. When $\mathrm{f}_{\mathrm{w}}=0,\left(\mathrm{SM}_{\mathrm{r}}\right.$, $\left.\tau_{\mathrm{r}}\right)$ is equal to $\left(\mathrm{SM}_{\mathrm{s}}, \tau_{\mathrm{s}}\right)$ for all cases. As predicted above, $\mathrm{SM}_{\mathrm{r}}$ increases with the water fraction and tends toward 1 when the whole scene is covered with water. For few cases $\left(\tau_{\mathrm{w}}=0\right.$, high $\mathrm{SM}_{\mathrm{s}}$ and $\left.\tau_{\mathrm{s}}\right)$, the retrieved $\mathrm{SM}_{\mathrm{r}}$ decreases for low water fractions. In average over all test cases, $\mathrm{SM}_{\mathrm{r}}$ is overestimated by $0.24 \mathrm{~m}^{3} \mathrm{~m}^{-3}$ with respect to $\mathrm{SM}_{\mathrm{s}}$ when $\mathrm{f}_{\mathrm{w}}$ $=0.5$. The retrieved L-VOD $\left(\tau_{\mathrm{r}}\right)$ slightly increases for low water fractions and low $\mathrm{SM}_{\mathrm{S}}(+10 \%$ in average), then decreases for increasing water fractions, proportionally to the initial $\tau_{s}$ value. It is particularly significant when the vegetation is submerged under water $\left(\tau_{\mathrm{w}}=0\right.$, left panel), especially since the total amount of visible vegetation decreases. $\tau_{\mathrm{r}}$ decreases by $74 \%$ in average when $f_{w}=0.5$, and drops to 0 when $f_{w}=1$ (full inundation). For the intermediate case of submerged vegetation amount (central panel), $\tau_{\mathrm{r}}$ decreases by $30 \%$ when $\mathrm{f}_{\mathrm{w}}=0.5$. When the vegetation is not submerged $\left(\tau_{\mathrm{w}}=\tau_{\mathrm{s}}\right.$, right panel), $\tau_{\mathrm{r}}$ values barely decrease, meaning a negligible impact of standing water, except for dense vegetation covers $\left(\tau_{\mathrm{s}} \geq 0.8,8 \%\right.$ decrease when $\left.\mathrm{f}_{\mathrm{w}}=1\right)$. In reality, the submerged vegetation is mostly low and sparse, whereas the emerging vegetation is mostly high and dense. Hence, the most representative cases are $\tau_{\mathrm{w}}=0$ with low $\tau_{\mathrm{s}}$ (bottom of the left panel), and $\tau_{\mathrm{w}}$ $=\tau_{\mathrm{s}}$ with high $\tau_{\mathrm{s}}$ (top of the right panel).

SMOS brightness temperature accuracy ( $3 \mathrm{~K}$ in average at $300 \mathrm{~K}$, McMullan et al., 2008) leads to an uncertainty on the derived L-VOD of $\sim 8 \%$. As a result, an anomalous drop in L-VOD during flooding should be well visible over submerged vegetation areas, such as grasslands, which present a drop of $74 \%$ in average for $\mathrm{f}_{\mathrm{w}}=0.5$ (Fig. 7). However, the drop should be barely visible over emerging flooded forest, which present a drop of $8 \%$ in average for $f_{w}=1$ (Fig. 7).

\subsubsection{Case B. Region based study over a representative year}

Here, the retrieval was computed over a representative year in the 

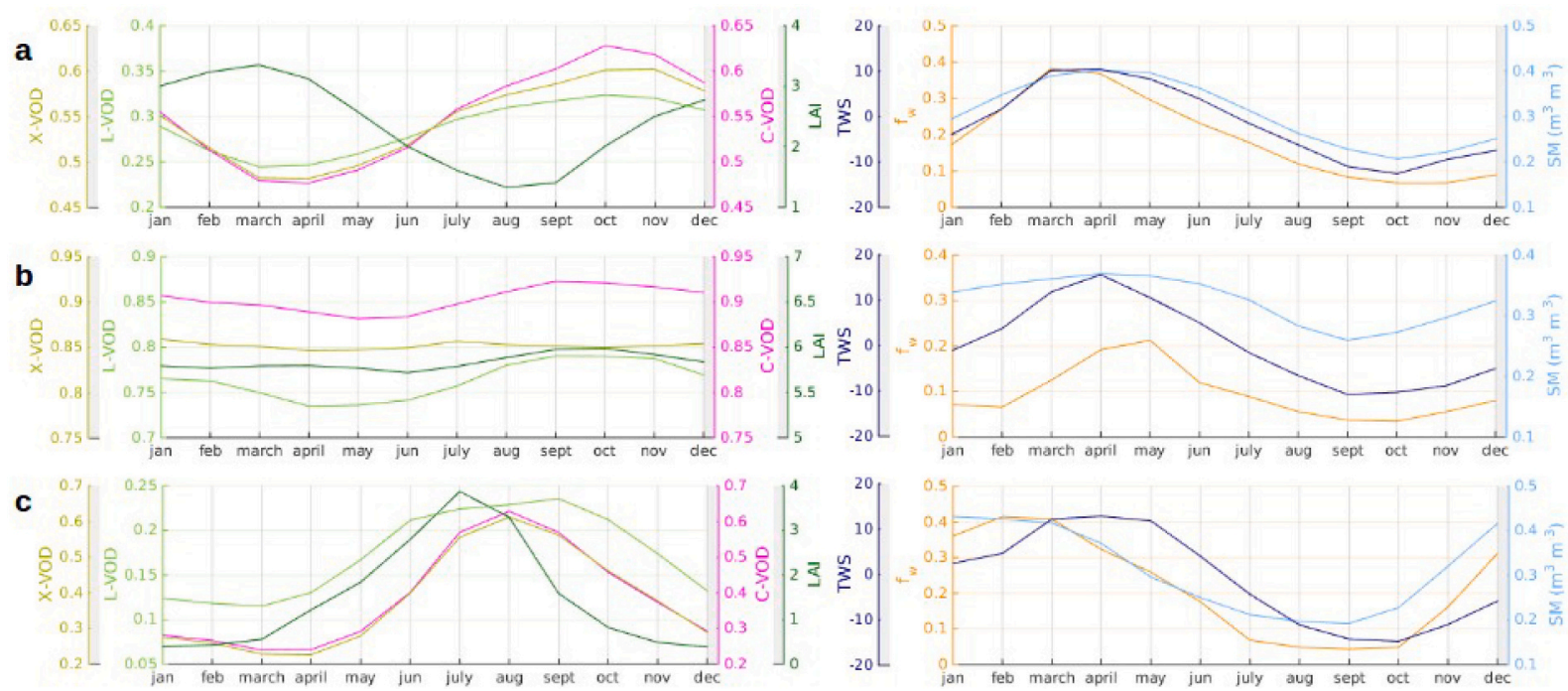

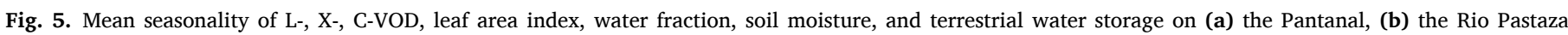

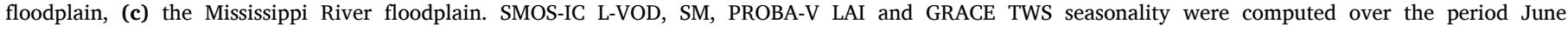

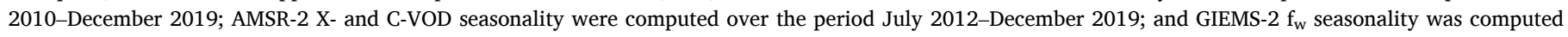
from June 2010 to December 2015.

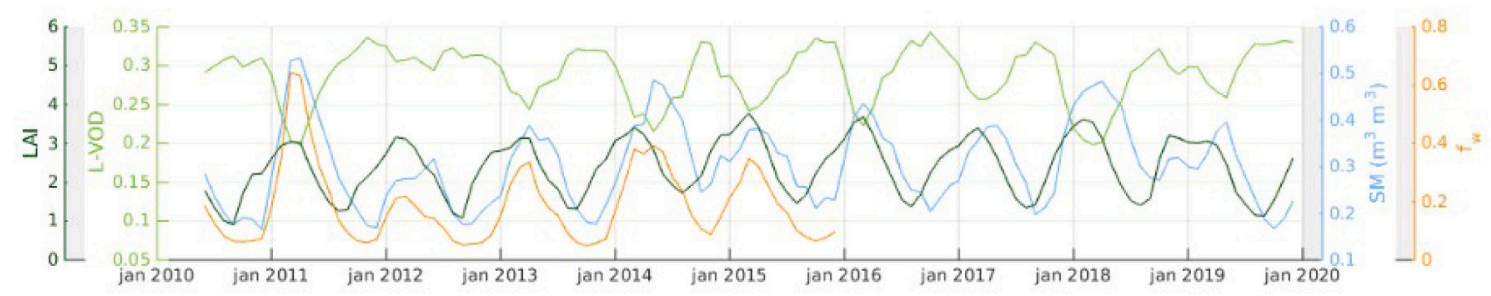

Fig. 6. Time series of remotely sensed leaf area index, L-VOD, soil moisture, and water fraction over the Pantanal, $2010-2019$.
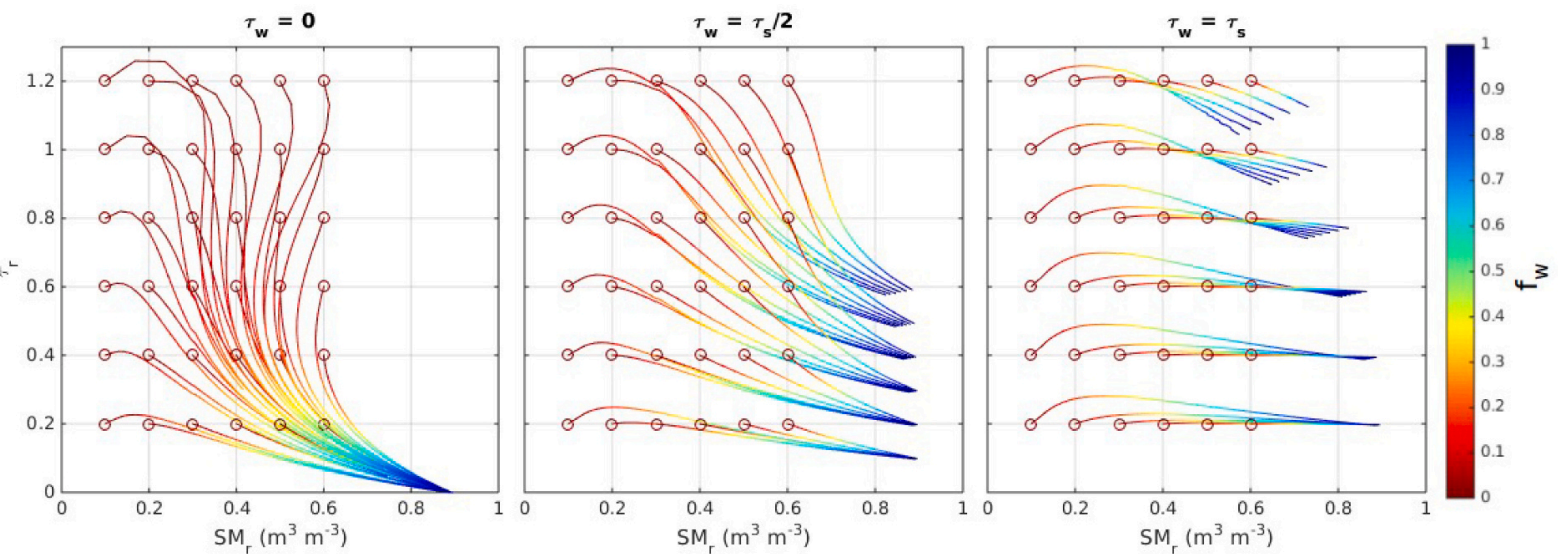

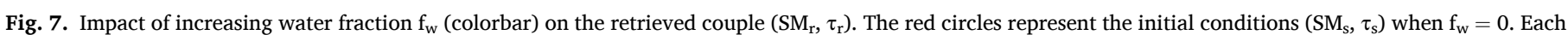

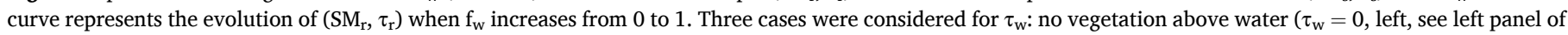

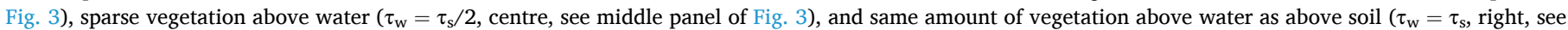
right panel of Fig. 3). (For interpretation of the references to colour in this figure legend, the reader is referred to the web version of this article.)

three study areas. For each pixel of each area, $\mathrm{f}_{\mathrm{w}}$ was from GIEMS-2 seasonality, $\mathrm{SM}_{\mathrm{s}}$ from SMOS-IC SM seasonality, and $\tau_{\mathrm{s}}$ from the maximum of SMOS-IC L-VOD seasonality. We considered static values of $\tau_{\mathrm{w}}=0.3 \times \tau_{\mathrm{s}}$ in the herbaceous Pantanal wetland and in the lower Mississippi River floodplain, and $\tau_{\mathrm{w}}=0.9 \times \tau_{\mathrm{s}}$ in the Rio Pastaza flooded forest (see Section 3.2.2). Monthly values of L-VOD, $\tau_{\mathrm{s}}$ and $\tau_{\mathrm{r}}$ were averaged over the area and are shown in Fig. 8. For the three cases, the retrieved $\tau_{\mathrm{r}}$ cycle is opposite to $\mathrm{SM}_{\mathrm{s}}$ and $\mathrm{f}_{\mathrm{w}}$ seasonality (Fig. 5, right panels). In the Pantanal wetland (Fig. $8 \mathrm{a}), \tau_{\mathrm{r}}$ has a significant amplitude of $0.09(26 \%)$, and $\tau_{\mathrm{r}}$ values are in good agreement with SMOS-IC L-VOD $\left(\right.$ std $\left.=5.310^{-3}\right)$. In the Rio Pastaza area (Fig. 8b), $\tau_{\mathrm{r}}$ shows a lower amplitude of $0.02(2.5 \%)$, because most of the vegetation remains above water (high $\tau_{\mathrm{w}}$ value of $0.9 \times \tau_{\mathrm{s}}$ ). $\tau_{\mathrm{r}}$ cycle is less similar to SMOS-IC LVOD cycle (std $=1.510^{-2}$ ), which has a higher seasonal amplitude 

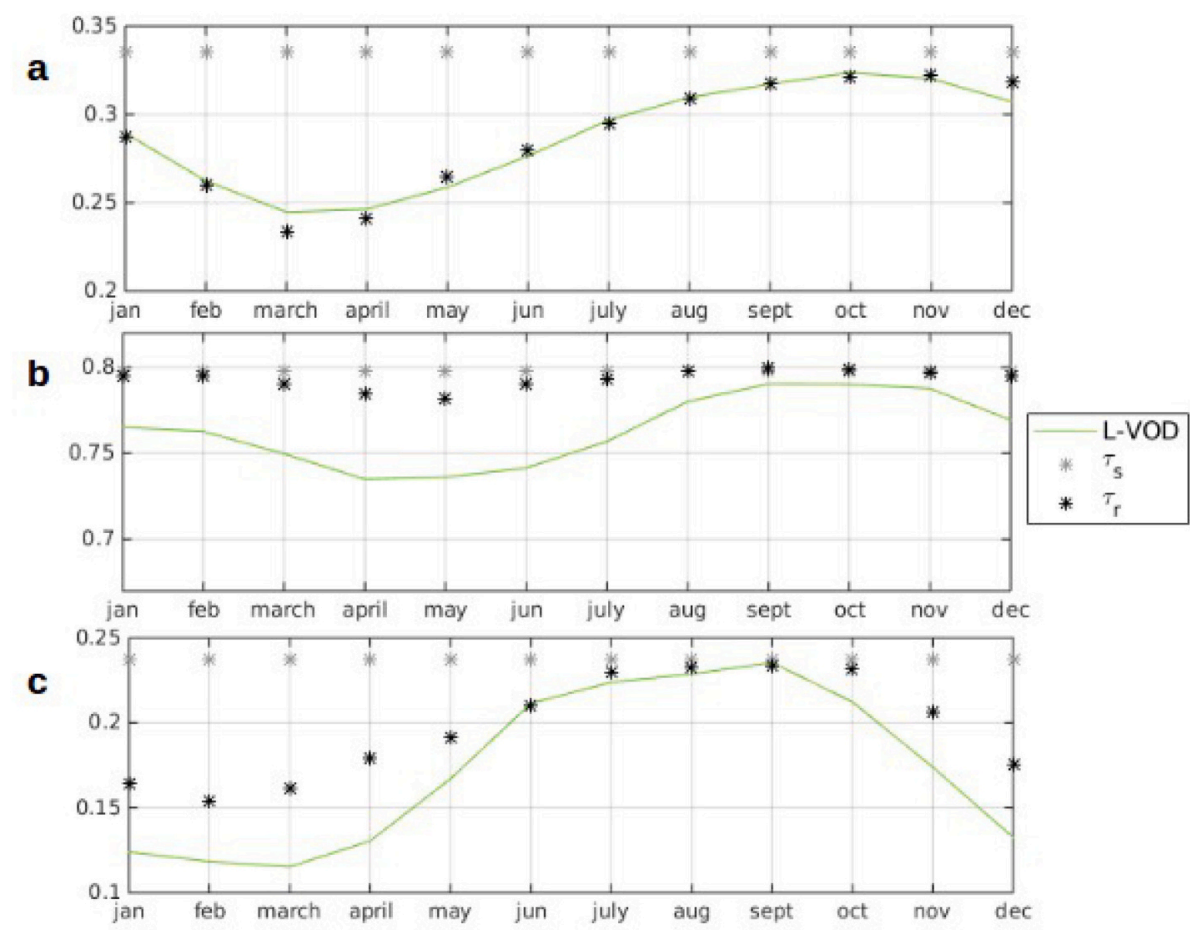

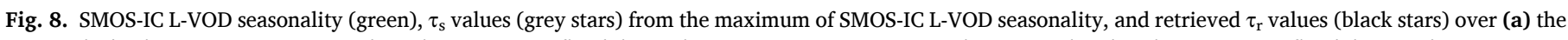

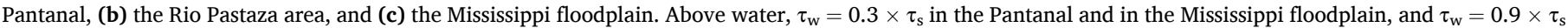
in the Rio Pastaza area. (For interpretation of the references to colour in this figure legend, the reader is referred to the web version of this article.)

(0.06, 7.5\%). In the lower Mississippi River floodplain (Fig. 8c), $\tau_{\mathrm{r}}$ amplitude is high $(0.08,35 \%)$, but SMOS-IC L-VOD amplitude is even higher $(0.12,50 \%)$. The deviation between SMOS-IC L-VOD and the retrieved $\tau_{\mathrm{r}}\left(\right.$ std $=1.810^{-2}$ ) can be explained by the inherent seasonal cycle of the vegetation in this temperate cropland (Table 4), which was not modelled here since $\tau_{\mathrm{s}}$ value is static. These results are further explained in Section 5.

\subsubsection{Case C. Global study}

The previous experiment was extended to the global scale, except for barren, urban, snow and ice land covers and areas covered with snow or ice in winter. For $\mathrm{f}_{\mathrm{w}}$, permanent water bodies were considered here in addition to seasonally inundated areas (see Section 3.2.2). The L-VOD error was averaged over a representative year and is shown in Fig. 9. As expected, negative L-VOD errors prevail around the major flooded areas;

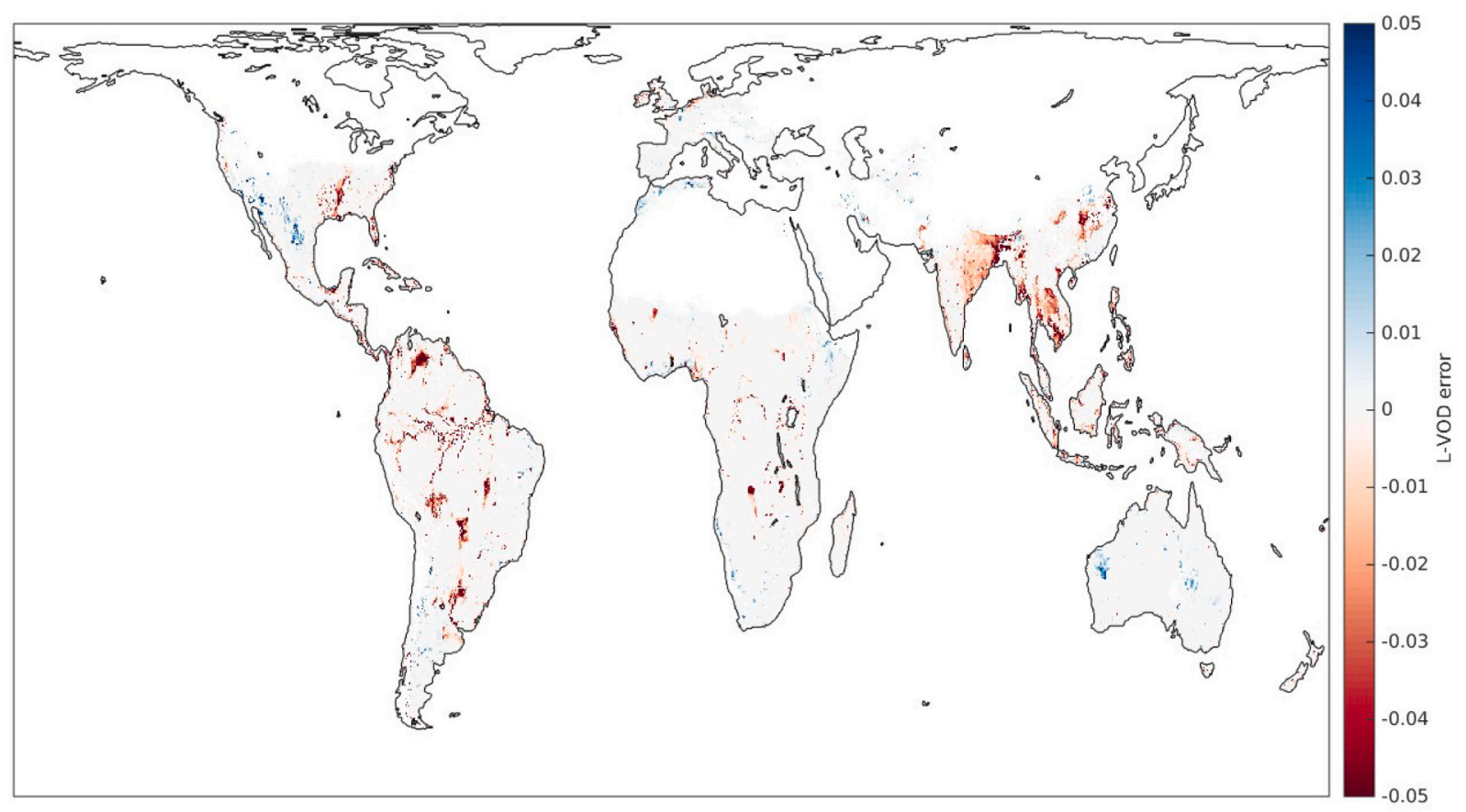

Fig. 9. Yearly average error in L-VOD at the global scale due to seasonal water dynamics and to non-excluded permanent water bodies ( $<20 \%$ of the pixel surface), computed with the difference $\tau_{\mathrm{r}}-\tau_{\mathrm{s}}$. Regions covered with snow in winter, barren, urban, snow and ice land cover classes were excluded. 
while positive L-VOD errors appear in areas cover with minor water bodies. These overestimations for low water fractions were already found in Fig. 7. The yearly average L-VOD error is close to -0.05 in largest wetlands, and can reach -0.15 at the maximum flood stage (Fig. S4). Positive errors can reach +0.03 in North-West America and in Australia.

\subsection{Impact on the aboveground biomass (AGB) estimation}

The global yearly average error in L-VOD computed previously (Fig. 9) was used to derive the error in AGB estimates, using Eq. (4) with the parameter values fitted with Baccini AGB (Table 3). The global map of AGB error computed with the mean curve of Baccini AGB is shown in Fig. 10. The minimum, mean and maximum values are provided in Table S1 for the 5th and 95th percentiles and the mean curve of the AGB distribution. The three curves result in similar values. At the global scale, errors in L-VOD linked with surface water have little impact on AGB estimates $\left(-0.6 \mathrm{Mg} \mathrm{ha}^{-1}\right.$ in average) while the errors are concentrated in areas subject to flooding. AGB errors are predominantly negative, and can reach $-15 /-20 \mathrm{Mg}^{-1}$ in the largest wetlands (Mississippi, South America, Africa and South-East Asia). Lower positive errors $\left(+3 \mathrm{Mg} \mathrm{ha}^{-1}\right)$ are found in North-West America and Australia, linked with low water fractions.

\section{Discussion}

Over seasonal wetlands, SMOS-IC L-VOD variations are negatively correlated with water availability in soil (Fig. 4), and have a significant while unexpected amplitude (Table 4). The L-VOD amplitude can increase by $50 \%$ in flooded areas and can reach the order of magnitude of the most pronounced inherent seasonal cycle of specific vegetation types. These results support previous observations of a strong decline in K-VOD during flooding by Jones et al. (2011).

Over the Pantanal wetland, the C-, X-, L-VOD cycles are completely opposite to $\mathrm{f}_{\mathrm{w}}, \mathrm{SM}$, TWS and LAI cycles (Fig. 5a), also confirming the observations of Jones et al. (2011) and Teubner et al. (2018). Ivory et al. (2019) showed that the Pantanal vegetation cycle follows closely the local flood stage, based on high resolution observations of MODIS EVI.
The VOD signals observed here are opposite to greening and to water availability, and reinforce the assumption of an anomalous L-VOD retrieval during inundations supported by a strong correlation between the magnitude of L-VOD drops and SM peaks (Fig. 4, Fig. 6), and between L-VOD drops and $\mathrm{f}_{\mathrm{w}}$ peaks (Fig. S2). In 2011, major rainfall linked with the La Niña event led to higher soil water content and extended inundated areas (Alho and Silva, 2012), and we observed the most significant drop in L-VOD of the period. Major floods also occurred in 2014 and 2018 (Espinoza et al., 2014), leading to same observations (high SM, low L-VOD). In contrast, the flooded area was reduced by $75 \%$ in 2012 compared to the 2000-2011 period, due to a decrease in rainfall during the rainy season (Moraes et al., 2013). L-VOD was particularly stable that year because the SMOS observation footprint was barely affected by the sparse inundations. This comment supports the assumption that the L-VOD in this area should be temporally stable, and should display a lower seasonal dynamic than what is currently derived. Same observations were made in the two other study areas (Fig. 5b, Fig. 5c, Fig. S1), except for the LAI cycle which is almost constant in the Rio Pastaza tropical dense forest, and strongly in phase with VOD in the Mississippi River floodplain, likely due to the strong seasonal cycle of the vegetation in this temperate cropland.

We provided here an explanation for the underestimation of L-VOD during flooding, linked with the fact that dynamic water fractions are not taken into account in SMOS (IC, Level2, and Level3), SMAP, nor in AMSR-2 retrievals. The decrease in brightness temperature values when the water fraction increases (Fig. S3) results in retrieved $\mathrm{SM}_{\mathrm{r}}$ values greater than real $\mathrm{SM}_{S}$ values, meaning that SMOS-IC SM values are overestimated during inundations, as expected (Fig. 7). In a few cases (high $\mathrm{SM}_{\mathrm{s}}$, high $\tau_{\mathrm{s}}$ ), $\mathrm{SM}_{\mathrm{r}}$ is underestimated during inundations, because the high $\tau$ hides the water-saturated soil underneath. To compensate for the presence of water, the system starts with significantly decreasing $\tau$ as it has more influence than SM for these particular conditions. It decreases also SM to a more relevant level for the emissivity to fit the observed angular signature. Once $\tau$ is low enough for the soil to contribute significantly, the system increases the SM along with $f_{w}$. Moreover, horizontal and vertical brightness temperatures generally diverge with increasing water fraction, leading to an underestimation of the retrieved L-VOD in most cases (Fig. 7). The underestimation is

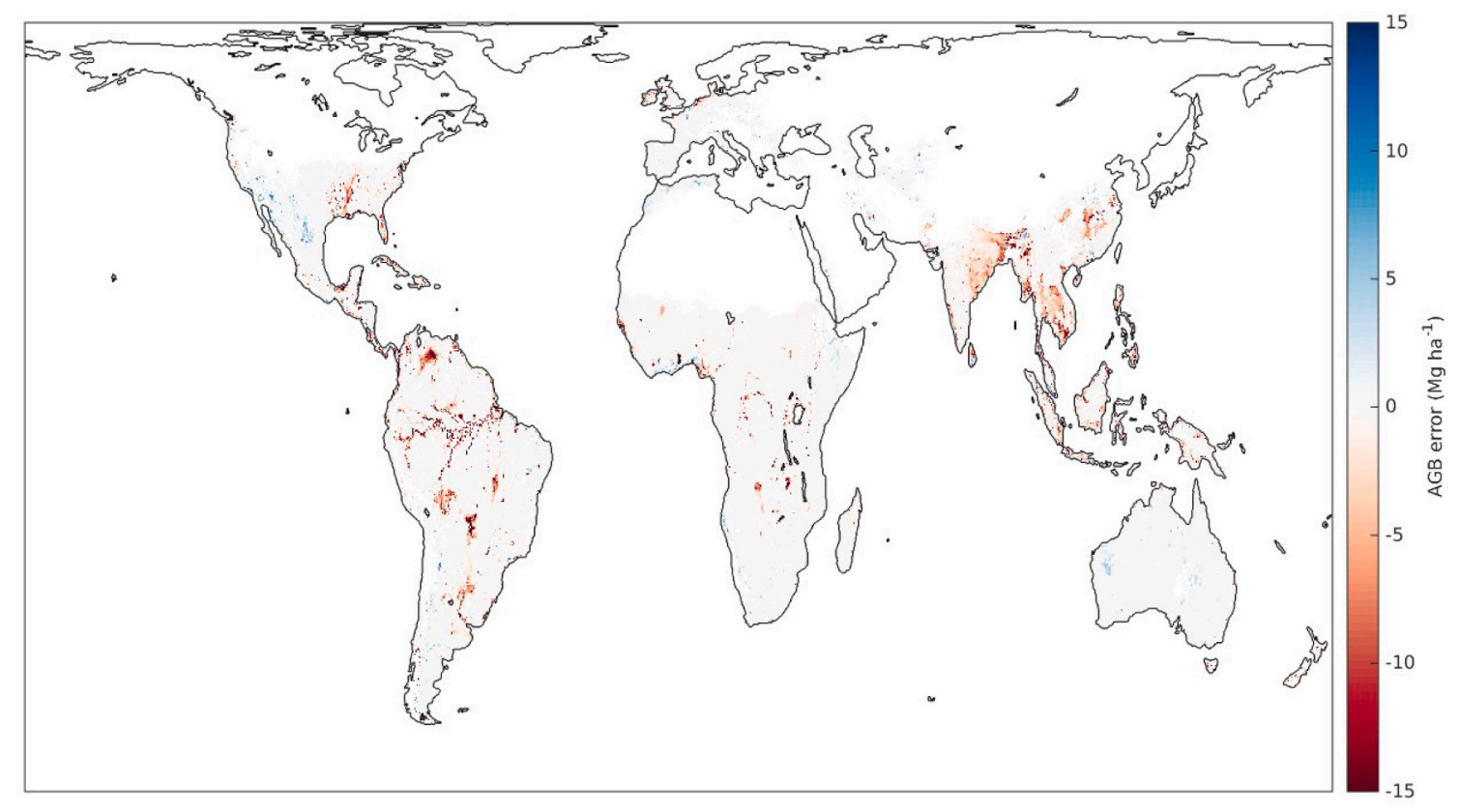

Fig. 10. $A G B$ error at the global scale $\left(\mathrm{Mg} \mathrm{ha}^{-1}\right)$ computed with the difference $\mathrm{AGB}_{\text {ini }}-\mathrm{AGB}_{\text {corr }}$, estimated with Eq. (4) and the parameter values fitted with the mean

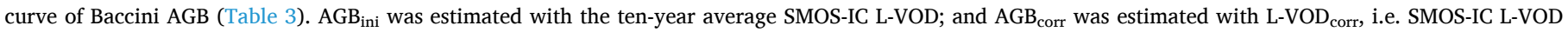
minus the yearly average error in L-VOD (Fig. 9). Regions covered with snow in winter, barren, urban, snow and ice land cover classes were excluded. 
particularly strong for low $\tau_{\mathrm{w}}$ values, especially since the total amount of emerging vegetation decreases. It is however not the only explanation as the L-VOD underestimation is higher than $50 \%$ when $f_{w}=0.5$. When the vegetation amount above water is the same as above soil $\left(\tau_{\mathrm{w}}=\tau_{\mathrm{s}}\right), \tau_{\mathrm{r}}$ values barely decrease with respect to $\tau_{\mathrm{s}}$. For low $\mathrm{f}_{\mathrm{w}}$ values, the L-VOD is overestimated by $10 \%$ in average. Further tests (Fig. S5) showed that adding open water in a scene decreases the brightness temperatures without significantly changing the difference $\mathrm{T}_{\mathrm{Bh}}-\mathrm{T}_{\mathrm{Bv}}$. The induced increase in SM decreases the TB but also increases the difference $T_{B h}$ $\mathrm{T}_{\mathrm{Bv}}$. The system has to increase slightly $\tau$ to compensate for this increase in $\mathrm{T}_{\mathrm{Bh}}-\mathrm{T}_{\mathrm{BV}}$, leading to the slight L-VOD overestimations observed. In practice, the most common situations are 1) submerged sparse vegetation areas (low $\tau_{\mathrm{s}}$ and low $\tau_{\mathrm{w}}$ ), and 2) emerging high vegetation areas (high $\tau_{\mathrm{s}}$ and high $\tau_{\mathrm{w}}$ ), in which cases L-VOD is underestimated during flooding.

These more realistic situations were depicted in Fig. 8. By imposing constant L-VOD initial conditions all year (i.e. a stable vegetation canopy), the retrievals over the Pantanal herbaceous swamp (Fig. 8a) and the Mississippi River floodplain (Fig. 8c) lead to a significant decrease in $\tau_{\mathrm{r}}$ values during flooding $(-0.09$ and -0.08 respectively). In the Pantanal, $\tau_{\mathrm{r}}$ reproduces well SMOS-IC in terms of value and of apparent seasonal cycle, strongly supporting that L-VOD is impacted by the dynamics of open water. More differences were found between SMOS-IC LVOD and $\tau_{\mathrm{r}}$ Over the Rio Pastaza flooded forest (Fig. $8 \mathrm{~b}$, std. $=1.510^{-2}$ ). They may be due to an erroneous estimation of $\tau_{\mathrm{w}}$ value $\left(0.9 \times \tau_{\mathrm{s}}\right)$, which was shown to have a major impact on the retrieved L-VOD (Fig. 7). $\tau_{\mathrm{w}}$ value was arbitrarily fixed, and can be overestimated if the flooded part of the area is less densely forested than the non-flooded part; or if the part of trees under water is higher than estimated. Actually, in Amazonian flooded forests, the water column can reach 10 to 15 $\mathrm{m}$ (Parolin et al., 2004). The water fraction $\mathrm{f}_{\mathrm{w}}$ can also be underestimated by GIEMS-2 dataset under flooded dense forest (Parrens et al., 2019). Finally, the vegetation itself may have a seasonal cycle, whereas we considered a static $\tau_{\mathrm{s}}$ value. This explanation also applies in the lower Mississippi River floodplain, mostly covered with croplands flourishing in spring and summer, where significant differences between SMOS-IC $\mathrm{L}$-VOD and $\tau_{\mathrm{r}}$ were found (std $=1.810^{-2}$ ). As a conclusion, the modelling showed that floods impact more significantly $\tau_{\mathrm{r}}$ values over low vegetation than over high vegetation, mostly due to the different amount of submerged vegetation. This remark explains why the impact of water on SMOS-IC L-VOD is mainly visible over waterlogged grasslands and low vegetation areas more than over flooded forests (Fig. 4). Moreover, as the measurement accuracy of the L-VOD is proportional to L-VOD values, the impact of dynamic water is more visible over low vegetation than over dense vegetation areas.

The extension of the modelling experiment to the global scale showed that L-VOD is predominantly underestimated in regions affected by seasonal flooding and by small water bodies (lakes, rivers or coastal areas). L-VOD can also be slightly overestimated in slightly inundated areas (North-West America, Australia). The yearly average error in LVOD is limited $(-0.05$ maximum), but can be significant at high flooding stages $(-0.15)$. The estimation of the global parameters is highly simplified and only aims to provide an order of magnitude of the global impact of surface water on L-VOD observations.

Consequently, the seasonal variations of surface water extent, if not accounted for in the retrieval, induce artificial seasonal cycles of VOD though eventually on top of the natural seasonal cycle of the vegetation. We also showed that even a small and static water fraction within a scene could alter L-VOD retrieved values. Taking into account the permanent water fractions as done for SMOS Level2 and Level3 algorithms could be an improvement for SMOS-IC algorithm.

L-VOD was employed to estimate and monitor aboveground biomass, using yearly averages of L-VOD to remove seasonal variations of VWC (Rodríguez-Fernández et al., 2018; Mialon et al., 2020; Fan et al., 2019). Our results show that AGB calculated using L-VOD can be underestimated up to $-15 /-20 \mathrm{Mg} \mathrm{ha}^{-1}$ over inundated regions (Fig. 10), possibly distorting the conclusions of regional studies. This impact is limited over forests, characterized by AGB values of $150-300 \mathrm{Mg} \mathrm{ha}^{-1}$, but can be significant over herbaceous wetlands with a typical AGB of $\sim 30 \mathrm{Mg} \mathrm{ha}^{-1}$. Larger AGB underestimations also occur under exceptional meteorological conditions, during El Niño or La Niña events for example. Studying the evolution trend of AGB (Brandt et al., 2018; Fan et al., 2019), in particular at high temporal frequency (Wigneron et al., 2020), should then consider the contribution of standing water if the study area presents large seasonally flooded areas.

\section{Conclusion}

In this study, we highlighted the anomalous decrease of VOD during flooding; and we showed with a modelling experiment that this phenomenon was linked to the influence of standing water temporal variations. SMOS Level2, Level3, and SMAP operational algorithms take the major water bodies into account with a static map, but this study showed the importance of considering the temporal dynamics of water extent. Indeed, it induces a strong decrease in the brightness temperatures of the scene, which in turn leads to an overestimation of SM and an underestimation of L-VOD, particularly significant over submerged vegetation areas (low vegetation). L-VOD tends toward 0 during total inundation, leading to an apparent asynchronous seasonal cycle with respect to other vegetation indices. Though less impacted, flooded forests are also affected.

The underestimation of L-VOD in areas affected by inundations can lead to a noticeable underestimation of the biomass amount $(-15 /-20$ $\mathrm{Mg} \mathrm{ha}^{-1}$ in the largest wetlands). It is thus important to better account for the open water extent and dynamics in $\mathrm{SM} / \tau$ retrieval algorithm. Submerged grasslands become open water areas, and should be filtered out during floods. Over higher vegetation, the retrieval algorithm could be revised to take the dynamic water fraction into account. The most important and most challenging aspect is to have access to reliable estimates of water bodies temporal evolution. GIEMS-2 dataset could be used for that purpose, as it is produced at a monthly time scale (Prigent et al., 2019).

\section{Declaration of Competing Interest}

The authors declare that they have no known competing financial interests or personal relationships that could have appeared to influence the work reported in this paper.

\section{Acknowledgements}

A.M., N.J.R.F., E.B., Y.H.K. acknowledge support by CNES (Centre National d'Etudes Spatiales) TOSCA program. SMOS-IC was obtained from the "Centre Aval de Traitement des Données SMOS" (CATDS), operated for the CNES (France) by IFREMER (Brest, France). The authors would like to thank the European Space Agency (ESA). AMSR-2 data were provided by Vrije Universiteit Amsterdam (Richard de Jeu) and NASA GSFC (Manfred Owe) (2014), AMSR2/GCOM-W1 surface soil moisture (LPRM) L3 1 day $25 \mathrm{~km} \times 25 \mathrm{~km}$ ascending V001, Edited by Goddard Earth Sciences Data and Information Services Center (GES DISC) (Bill Teng), Greenbelt, MD, USA, Goddard Earth Sciences Data and Information Services Center (GES DISC), Accessed: 29/07/2020, doi:https://doi.org/10.5067/M5DTR2QUYLS2. TWS data were obtained from GravIS web portal, the Gravity Information Service of the German Research Centre for Geosciences (GFZ). LAI data came from Copernicus Global Land Service Portal (Copernicus Service information, 2020). IMS Daily Northern Hemisphere Snow and Ice Analysis at $4 \mathrm{~km}$ resolution, Version 1, came from the United States National Ice Center (USNIC), Boulder, Colorado USA, delivered by the National Snow and Ice Data Center (NSIDC), doi: https://doi.org/10.7265/N52R3P, Accessed: 01/ 08/2020. 
Appendix A. Supplementary data

Supplementary data to this article can be found online at https://doi. org/10.1016/j.rse.2021.112345.

\section{References}

Alho, C.J., Silva, J.S., 2012. Effects of severe floods and droughts on wildlife of the Pantanal wetland (Brazil) - a review. Animals 2 (4), 591-610.

Baccini, A., Goetz, S., Walker, W., Laporte, N., Sun, M., Sulla- Menashe, D., Hackler, J., Beck, P., Dubayah, R., Friedl, M., Samanta, S., 2012. Estimated carbon dioxide emissions from tropical deforestation improved by carbon-density maps. Nat. Clim. Chang. 2, 182-185.

Bernal, C., Christophoul, F., Darrozes, J., Laraque, A., Bourrel, L., Soula, J.C., Guyot, J.L. Baby, P., 2013. Crevassing and capture by floodplain drains as a cause of partial avulsion and anastomosis (lower Rio Pastaza, Peru). J. S. Am. Earth Sci. 44, 63-74.

Boergens, E., Dobslaw, H., Dill, R., 2019. GFZ GravIS RL06 Continental Water Storage Anomalies, V. 0002. Services, GFZ Data. https://doi.org/10.5880/GFZ.GRAVIS_06 L3_TWS.

Brandt, M., Wigneron, J.P., Chave, J., Tagesson, T., Penuelas, J., Ciais, P., Rasmussen, K., Tian, F., Mbow, C., Al-Yaari, A., Rodriguez-Fernandez, N.J., Schurgers, G. Zhang, W., Chang, J., Kerr, Y.H., Verger, A., Tucker, C., Mialon, A., Vang Rasmussen, L., Fan, L., Fensholt, R., 2018. Satellite passive microwaves reveal recent climate-induced carbon losses in african drylands. Nat. Ecolo. Evol. 2 (5), 827.

Brodzik, M.J., Billingsley, B., Haran, T., Raup, B., Savoie, M.H., 2012. EASE-grid 2.0: incremental but significant improvements for earth-gridded data sets. ISPRS Int. J. Geo Inf. 1, 32-45.

Broxton, P.D., Zeng, X., Sulla-Menashe, D., Troch, P.A., 2014. A global land cover climatology using MODIS data. J. Appl. Meteorol. Climatol. 53, 1593-1605.

Campos-Taberner, M., García-Haro, F.J., Busetto, L., Ranghetti, L., Martínez, B., Gilabert, M.A., Camps-Valls, G., Camacho, F., Boschetti, M., 2018. A critical comparison of remote sensing leaf area index estimates over rice-cultivated areas: from Sentinel-2 and Landsat-7/8 to MODIS, GEOV1 and EUMETSAT polar system. Remote Sens. 10 (5), 763.

Du, J., Kimball, J.S., Jones, L.A., Kim, Y., Glassy, J., Watts, J.D., 2017. A global satellite environmental data record derived from AMSR-E and AMSR2 microwave Earth observations. Earth Syst. Sci. Data 9 (2), 791-808.

Escorihuela, M.J., Kerr, Y.H., de Rosnay, P., Wigneron, J.P., Calvet, J.C., Lemaitre, F., 2007. A simple model of the bare soil microwave emission at L-band. IEEE Trans. Geosci. Remote Sens. 45 (7), 1978-1987.

Espinoza, J.C., Marengo, J.A., Ronchail, J., Carpio, J.M., Flores, L.N., Guyot, J.L., 2014. The extreme 2014 flood in South-Western Amazon basin: the role of tropicalsubtropical South Atlantic SST gradient. Environ. Res. Lett. 9 (12), 124007.

Fan, L., Wigneron, J.P., Ciais, P., Chave, J., Brandt, M., Fensholt, R., Saatchi, S.S. Bastos, A., Al-Yaari, A., Hufkens, K., Qin, Y., Xiao, X., Chen, C., Myneni, R.B., Fernandez-Moran, R., Mialon, A., Rodriguez-Fernandez, N.J., Kerr, Y.H., Tian, F. Peñuelas, J., 2019. Satellite-observed pantropical carbon dynamics. Nat. plants 5 (9), 944-951.

Fernandez-Moran, R., Al-Yaari, A., Mialon, A., Mahmoodi, A., Al Bitar, A., De Lannoy, G., Rodriguez-Fernandez, N., Lopez-Baeza, E., Kerr, Y.H., Wigneron, J.P., 2017. SMOSIC: An alternative SMOS soil moisture and vegetation optical depth product. Remote Sensing 9 (5), 457.

Ferrazzoli, P., Guerriero, L., Wigneron, J.P., 2002. Simulating L-band emission of forests in view of future satellite applications. IEEE Trans. Geosci. Remote Sens. 40 (12), 2700-2708.

Fuster, B., Sánchez-Zapero, J., Camacho, F., García-Santos, V., Verger, A., Lacaze, R., Weiss, M., Baret, F., Smets, B., 2020. Quality assessment of PROBA-V LAI, fAPAR and fCOVER collection $300 \mathrm{~m}$ products of Copernicus global land service. Remote Sens. 12 (6), 1017.

GDAL/OGR contributors, 2020. GDAL/OGR Geospatial Data Abstraction software Library. Open Source Geospatial Foundation. https://gdal.org.

Gonçalves, H.C., Mercante, M.A., Santos, E.T., 2011. Hydrological cycle. Braz. J. Biol. 71 241-253.

Helfrich, S., McNamara, D., Ramsay, B., Baldwin, T., Kasheta, T., 2007. Enhancements to, and forthcoming developments in the interactive multisensor snow and ice mapping system (IMS). Hydrol. Proc. 21 (12), 1576-1586.

Imaoka, K., Kachi, M., Kasahara, M., Ito, N., Nakagawa, K., Oki, T., 2010. Instrument performance and calibration of AMSR-E and AMSR2. Int. Arch. Photogr. Remote Sens. Spatial Info. Sci. 38 (8), 13-18.

Ivory, S.J., McGlue, M.M., Spera, S., Silva, A., Bergier, I., 2019. Vegetation, rainfall, and pulsing hydrology in the Pantanal, the world's largest tropical wetland. Environ. Res. Lett. 14 (12), 124017.

Jackson, T.J., Schmugge, T.J., 1991. Vegetation effects on the microwave emission of soils. Remote Sens. Environ. 36, 203-212.

Jones, M.O., Jones, L.A., Kimball, J.S., McDonald, K.C., 2011. Satellite passive microwave remote sensing for monitoring global land surface phenology. Remote Sens. Environ. 115 (4), 1102-1114.

Jones, M.O., Kimball, J.S., Nemani, R.R., 2014. Asynchronous Amazon forest canopy phenology indicates adaptation to both water and light availability. Environ. Res. Lett. 9 (12), 124021.

Kalliola, R., Puhakka, M., Salo, J., Tuomisto, H., Ruokolainen, K., 1991. The Dynamics, Distribution and Classification of Swamp Vegetation in Peruvian Amazonia. The Finnish Botanical Publishing Board, Annales Botanici Fennici, pp. 225-239.
Kawanishi, T., Sezai, T., Ito, Y., Imaoka, K., Takeshima, T., Ishido, Y., Shibata, A., Miura, M., Inahata, H., Spencer, R.W., 2003. The advanced microwave scanning radiometer for the earth observing system (AMSR-E), NASDA's contribution to the EOS for global energy and water cycle studies. IEEE Trans. Geosci. Remote Sens. 41 (2), 184-194.

Kerr, Y.H., Waldteufel, P., Wigneron, J.P., Martinuzzi, J.A.M.J., Font, J., Berger, M., 2001. Soil moisture retrieval from space: the soil moisture and ocean salinity (SMOS) mission. IEEE Trans. Geosci. Remote Sens. 39 (8), 1729-1735.

Kerr, Y.H., Waldteufel, P., Wigneron, J.P., Delwart, S., Cabot, F., Boutin, J., Escorihuela, M.J., Font, J., Reul, N., Gruhier, C., Juglea, S.E., Drinkwater, M.R., Hahne, A., Martin-Neira, M., Mecklenburg, S., 2010. The SMOS mission: new tool for monitoring key elements of the global water cycle. Proc. IEEE 98 (5), 666-687.

Kerr, Y.H., Waldteufel, P., Richaume, P., Wigneron, J.P., Ferrazzoli, P., Mahmoodi, A., Al Bitar, A., Cabot, F., Gruhier, C., Juglea, S.E., Leroux, D., Mialon, A., Delwart, S., 2012. The SMOS soil moisture retrieval algorithm. Geosci. Remote Sens. 50 (5), 1384-1403.

Kerr, Y.H., Richaume, P., Waldteufel, P., Ferrazzoli, P., Wigneron, J.P., Schwank, M., Rautiainen, K., 2020. SMOS Level 2 Processor Soil Moisture Algorithm Theoretical Basis Document (ATBD). SM-ESL (CBSA), CESBIO, Toulouse, SO-TN-ESL-SM-GS0001-4b, p. 145.

Klein, L.A., Swift, C.T., 1977. An improved model for the dielectric constant of sea water at microwave frequencies. IEEE Trans. Antennas Propag. AP-25 (1), 104-111.

Liu, Y.Y., Van Dijk, A.I., De Jeu, R.A., Canadell, J.G., McCabe, M.F., Evans, J.P., Wang, G., 2015. Recent reversal in loss of global terrestrial biomass. Nat. Clim. Chang. 5 (May), 1-5.

McMullan, K.D., Brown, M.A., Martín-Neira, M., Rits, W., Ekholm, S., Marti, J., Lemanczyk, J., 2008. SMOS: the payload. IEEE Trans. Geosci. Remote Sens. 46 (3), 594-605.

Mialon, A., Rodríguez-Fernández, N.J., Santoro, M., Saatchi, S., Mermoz, S., Bousquet, E., Kerr, Y.H., 2020. Evaluation of the sensitivity of SMOS L-VOD to Forest above-ground biomass at global scale. Remote Sens. 12 (9), 1450.

Mo, T., Choudhury, B.J., Schmugge, T.J., Wang, J.R., Jackson, T.J., 1982. A model for microwave emission from vegetation-covered fields. J. Geophys. Res. 87, 11.229-11.237.

Moraes, E.C., Pereira, G., da Silva Cardozo, F., 2013. Evaluation of reduction of Pantanal wetlands in 2012. Geografia 38, 81-93.

Noy-Meir, I., 1973. Desert ecosystems: environment and producers. Annu. Rev. Ecol. Syst. 4 (1), 25-51.

Owe, M., de Jeu, R., Holmes, T., 2008. Multisensor historical climatology of satellitederived global land surface moisture. J. Geophys. Res.: Earth Surf. 113, F01002.

Parolin, P., Ferreira, L.V., Albernaz, A.L.K.M., Almeida, S.S., 2004. Tree species distribution in Várzea forests of Brazilian Amazonia. Folia Geobot 39, 371-383.

Parrens, M., Al Bitar, A., Frappart, F., Paiva, R., Wongchuig, S., Papa, F., Yamasaki, D., Kerr, Y., 2019. High resolution mapping of inundation area in the Amazon basin from a combination of L-band passive microwave, optical and radar datasets. Int. J. Appl. Earth Obs. Geoinf. 81, 58-71.

Piao, S., Wang, X., Park, T., Chen, C., Lian, X., He, Y., Bjerke, J.W., Chen, A., Ciais, P., Tommervik, H., Nemani, R.R., Myneni, R.B., 2019. Characteristics, drivers and feedbacks of global greening. Nat. Rev. Earth Environ. 1-14.

Piazza, B.P., Allen, Y.C., Martin, R., Bergan, J.F., King, K., Jacob, R., 2015. Floodplain conservation in the Mississippi River valley: combining spatial analysis, landowner outreach, and market assessment to enhance land protection for the Atchafalaya River basin, Louisiana, USA. Restor. Ecol. 23 (1), 65-74.

Prigent, C., Matthews, E., Aires, F., Rossow, W.B., 2001. Remote sensing of global wetland dynamics with multiple satellite data sets. Geophys. Res. Lett. 28, 4631-4634.

Prigent, C., Papa, F., Aires, F., Rossow, W.B., Matthews, E., 2007. Global inundation dynamics inferred from multiple satellite observations, 1993-2000. J. Geophys. Res, 112, D12107.

Prigent, C., Jimenez, C., Bousquet, P., 2019. Satellite-derived global surface water extent and dynamics over the last 25 years (GIEMS-2). J. Geophys. Res.-Atmos. 125, e2019JD030711.

Qin, Y., Xiao, X., Dong, J., Zhang, Y., Wu, X., Shimabukuro, Y., Arai, E., Biradar, C., Wang, J., Zou, Z., Liu, F., Shi, Z., Doughty, R., Moore, B., 2019. Improved estimates of forest cover and loss in the Brazilian Amazon in 2000-2017. Nat. Sust. 2 (8), 764-772.

Rahmoune, R., Ferrazzoli, P., Singh, Y.K., Kerr, Y.H., Richaume, P., Al Bitar, A., 2014 SMOS retrieval results over forests: comparisons with independent measurements. IEEE J. Selected Topics Appl. Earth Observ. Remote Sens. 7 (9), 3858-3866.

Rodríguez-Fernández, N.J., Mialon, A., Mermoz, S., Bouvet, A., Richaume, P., Al Bitar, A., Al-Yaari, A., Brandt, M., Kaminski, T., Le Toan, T., Kerr, Y.H., Wigneron, J. P., 2018. An evaluation of SMOS L-band vegetation optical depth (L-VOD) data sets: high sensitivity of L-VOD to above-ground biomass in Africa. Biogeosciences 15 (14).

Teubner, I.E., Forkel, M., Jung, M., Liu, Y.Y., Miralles, D.G., Parinussa, R., van der Schalie, R., Vreugdenhil, M., Schwalm, C.R., Tramontana, G., Camps-Valls, G., Dorigo, W.A., 2018. Assessing the relationship between microwave vegetation optical depth and gross primary production. Int. J. Appl. Earth Obs. Geoinf. 65, 79-91.

Tian, F., Wigneron, J.P., Ciais, P., Chave, J., Ogée, J., Penuelas, J., Ræbild, A., Domec, J. C., Tong, X., Brandt, M., Mialon, A., Rodriguez-Fernandez, N., Tagesson, T., AlYaari, A., Kerr, Y.H., Chen, C., Myneni, R.B., Zhang, W., Ardö, J., Fensholt, R., 2018. Coupling of ecosystem-scale plant water storage and leaf phenology observed by satellite. Nat. Ecol. Evol. 2 (9), 1428.

Ulaby, F.T., Moore, R.K., Fung, A.K., 1981. Microwave Remote Sensing: Active and Passive. volume 1-Microwave Remote Sensing Fundamentals and Radiometry. 
Verger, A., Baret, F., Weiss, M., 2014. Near real-time vegetation monitoring at global scale. IEEE J. Selected Topics Appl. Earth Observ. Remote Sens. 7, 3473-3481.

Vittucci, C., Ferrazzoli, P., Kerr, Y.H., Richaume, P., Laurin, G.V., Guerriero, L., 2018. Analysis of vegetation optical depth and soil moisture retrieved by SMOS over tropical forests. IEEE Geosci. Remote Sens. Lett. 16 (4), 504-508.

Vittucci, C., Laurin, G.V., Tramontana, G., Ferrazzoli, P., Guerriero, L., Papale, D., 2019. Vegetation optical depth at L-band and above ground biomass in the tropical range: evaluating their relationships at continental and regional scales. Int. J. Appl. Earth Obs. Geoinf. 77, 151-161.

Wang, J.R., Choudhury, B.J., 1981. Remote sensing of soil moisture content, over bare field at 1.4 GHz frequency. J. Geophys. Res. Oceans 86, 5277-5282.

Wigneron, J.P., Laguerre, L., Kerr, Y.H., 2001. A simple parameterization of the L-band microwave emission from rough agricultural soils. IEEE Trans. Geosci. Remote Sens. 39 (8), 1697-1707.
Wigneron, J.P., Kerr, Y., Waldteufel, P., Saleh, K., Escorihuela, M.J., Richaume, P., Ferrazzoli, P., de Rosnay, P., Gurney, R., Calvet, J.C., Grant, J., Guglielmetti, M., Hornbuckle, B., Mätzler, C., Pellarin, T., Schwank, M., 2007. L-band microwave emission of the biosphere (L-MEB) model: description and calibration against experimental data sets over crop fields. Remote Sens. Environ. 107, 639-655.

Wigneron, J.P., Fan, L., Ciais, P., Bastos, A., Brandt, M., Chave, J., Saatchi, S., Baccini, A., Fensholt, R., 2020. Tropical forests did not recover from the strong 2015-2016 El Niño event. Sci. Adv. 6 (6), eaay4603.

Ye, N., Walker, J.P., Guerschman, J., Ryu, D., Gurney, R.J., 2015. Standing water effect on soil moisture retrieval from L-band passive microwave observations. Remote Sens. Environ. 169, 232-242. 